Federal Reserve Bank of Dallas

Globalization and Monetary Policy Institute

Working Paper No. 17

http://www.dallasfed.org/assets/documents/institute/wpapers/2008/0017.pdf

\title{
The Real Exchange Rate in Sticky Price Models: Does Investment Matter?*
}

\author{
Enrique Martinez-Garcia \\ Federal Reserve Bank of Dallas \\ Jens Søndergaard \\ Bank of England
}

July 2008

\begin{abstract}
This paper re-examines the ability of sticky-price models to generate volatile and persistent real exchange rates. We use a DSGE framework with pricing-to-market akin to those in Chari, et al. (2002) and Steinsson (2008) to illustrate the link between real exchange rate dynamics and what the model assumes about physical capital. We show that adding capital accumulation to the model facilitates consumption smoothing and significantly impedes the model's ability to generate volatile real exchange rates. Our analysis, therefore, caveats the results in Steinsson (2008) who shows how real shocks in a sticky-price model without capital can replicate the observed real exchange rate dynamics. Finally, we find that the CKM (2002) persistence anomaly remains robust to several alternative capital specifications including set-ups with variable capital utilization and investment adjustment costs (see, e.g., Christiano, et al., 2005). In summary, the PPP puzzle is still very much alive and well.
\end{abstract}

JEL codes: F31, F37, F41

\footnotetext{
* Enrique Martinez-Garcia, Research Department, Federal Reserve Bank of Dallas, 2200 N. Pearl Street, Dallas, TX 75201.+1 (214) 922- 5262. enrique.martinez-garcia@dal.frb.org. Jens Søndergaard, Monetary Instruments and Markets Division, Monetary Analysis, Bank of England. Threadneedle Street, London EC2R 8AH, UK. +44 (0)20 7601-4869. jens.sondergaard@bankofengland.co.uk. We would like to thank Mark Astley, Charles Engel, Alberto Musso, Roman Sustek, Jian Wang, Mark Wynne, Wenjuan Xie, and many seminar and conference participants at the Midwest Macro Meetings 2008 for helpful discussions. We also acknowledge the excellent research assistance provided by Artis Frankovics, and the support of the Federal Reserve Bank of Dallas and the Bank of England. All remaining errors are ours alone. The views in this paper do not necessarily reflect the views of the Bank of England, Federal Reserve Bank of Dallas or the Federal Reserve System.
} 


\section{Introduction}

Understanding the short-run dynamics of real exchange rates remains a key issue on the open economy research agenda. Standard international macro models have had difficulty replicating real exchange rates that are both very volatile and highly persistent in the data. One recent strand of research has revived the Dornbusch (1976a, 1976b) 'exchange rate overshooting' hypothesis arguing that exchange rate volatility is essentially driven by monetary shocks interacting with sticky prices. For instance, Chari, et al. (2002) (CKM) have shown how a two-country sticky-price model with pricing-to-market driven by monetary shocks has the potential to simultaneously match the volatility of U.S. output and real exchange rates, hence resolving the so-called international pricing puzzle. But their model does not reproduce the persistence of real exchange rates and, thus, fails to address the persistence anomaly. Steinsson (2008), however, appears to resolve both the international pricing puzzle and the persistence anomaly (jointly referred to as the PPP puzzle) with real shocks and a sticky-price model with no capital.

In this paper, we use a DSGE framework akin to those in CKM (2002) and Steinsson (2008) to illustrate the link between real exchange rate dynamics and what the model assumes about capital. We find that omitting capital is not inconsequential in terms of the model's ability to resolve the PPP puzzle. Our benchmark model featuring complete asset markets, capital accumulation and investment adjustment costs matches the real exchange rate persistence with real shocks, but generates less real exchange rate volatility relative to a similar setup without capital. Furthermore, the same benchmark model replicates the observed real exchange volatility with monetary policy shocks, but not the persistence.

In other words, for real shocks, our benchmark reverses some of the promising results presented by Steinsson (2008) on the international pricing puzzle; for monetary shocks, it confirms the persistence anomaly

discussed by CKM (2002) as a robust fact. A first-pass reading of our results suggests that adding capital to a sticky-price model takes us effectively "back to square one" in terms of resolving the PPP puzzle.

To understand our results, we must consider the role of capital accumulation in an open-economy model. Access to capital accumulation facilitates intertemporal consumption smoothing, since it allows households to adjust their investment-savings margin in response to country-specific shocks. Adjusting through the intertemporal margin has the potential to generate a very smooth series for consumption and the real exchange rate.

However, the ability to smooth consumption hinges on how costly it is for households to adjust their capital stock. To illustrate this, our benchmark specification introduces investment adjustment costs similar to those in Christiano, et al. (2005). The adjustment costs regulate the volatility of investment, but also affect the volatility and cross-correlation of consumption. A direct implication of the complete asset markets assumption is that consumption and the real exchange rate are linked together in the model. Adjustment costs make it more costly to smooth consumption through the intertemporal margin, hence consumption and (by extension) the real exchange rate become more volatile.

Capital utilization offers a way for households to get around the investment constraints imposed by the adjustment costs. We show that adding capital utilization to the model as in Christiano, et al. (2005) facilitates further consumption smoothing which, in turn, reduces the model's ability to produce highly volatile real exchange rates. Low real exchange rate volatility is also robust after the inclusion of investmentspecific shocks as in Greenwood, et al. (1988). While Justiniano and Primiceri (2008) have highlighted the importance of these shocks in a closed economy setting, our benchmark calibration suggests that the same 
shocks cannot fully account for consumption and real exchange rate volatilities in an open-economy setting. So resolving the international pricing puzzle remains challenging.

Addressing the CKM (2002) persistence anomaly is not easy either. Our results suggest that the persistence anomaly in response to monetary shocks is robust to adding capital back into the model, to the specification of the adjustment cost function, and even to the addition of capital utilization. High persistence is easier to get from real shocks since they trigger an endogenous monetary policy reaction that implies a hump-shaped consumption response. As shown by Steinsson (2008), this hump-shaped response is important to produce high real exchange rate persistence. But our paper argues that with real shocks is rather difficult to match the volatility of the real exchange rate, if the model features capital.

In our view, the PPP puzzle is still very much alive and well in the context of the open-economy, stickyprice model. Our results suggest that models without capital tend to suffer from a 'volatility bias' that understates the true magnitude of the international pricing puzzle. Tackling the PPP puzzle requires a two-pronged modelling strategy. The first prong is to build a model with capital that can generate very volatile real exchanges rates stemming from a combination of real and other shocks (including monetary policy shocks). The second prong entails looking for ways to ensure sufficient persistence.

Therefore, the key challenge is to find open-economy models that clearly break the link between the real exchange rates and real quantities (particularly, consumption). Recent research has presented various options including informational frictions (e.g., Martínez-García, 2008), asymmetric price stickiness (e.g., Benigno, 2004, Carvalho and Nechio, 2008), asymmetric monetary policy rules (e.g., Groen and Matsumoto, 2004), alternative financial market structures (e.g., Heathcote and Perri, 2002), and co-integrated, unit-root technology shocks (e.g., Rabanal, et al., 2008). Future research may need to incorporate some of these features and further re-examine the ability of the open-economy, sticky-price framework to generate volatile and persistent real exchange rates as well as realistic business cycles.

The paper is structured as follows. Section 2 contains a description of our two-country model with capital accumulation, while section 3 outlines our calibration strategy for the simulations. Section 4 summarizes the quantitative findings, and section 5 the sensitivity analysis. Section 6 concludes.

\section{The Open Economy Model}

Here, we describe the model and the log-linearized equilibrium conditions simultaneously. As a notational convention, any variable identified with lower-case letters and a caret on top represents a transformation (expressed in log deviations relative to steady state) of the corresponding variable in upper-case letters. See the companion working paper (Martínez-García and Søndergaard, 2008) for more details on the equilibrium conditions, and the log-linearization approach.

\subsection{The Intertemporal Consumption and Savings Problem}

We specify a stochastic, two-country general equilibrium model. Each country is populated by a continuum of infinitely lived (and identical) households in the interval $[0,1]$. In each period, the domestic household's utility function is additively separable in consumption, $C_{t}$, and labor, $L_{t}$. Domestic households maximize,

$$
\sum_{\tau=0}^{\infty} \beta^{\tau} \mathbb{E}_{t}\left[\frac{1}{1-\sigma^{-1}}\left(C_{t+\tau}\right)^{1-\sigma^{-1}}-\frac{1}{1+\varphi}\left(L_{t+\tau}\right)^{1+\varphi}\right]
$$


where $\beta \in(0,1)$ is the subjective intertemporal discount factor. The elasticity of intertemporal substitution satisfies that $\sigma>0(\sigma \neq 1)$, while the inverse of the Frisch elasticity of labor supply satisfies that $\varphi>0$.

We assume that households in either country have unrestricted access to a complete set of contingent claims, traded internationally. The domestic household maximizes its lifetime utility in (1) subject to the sequence of budget constraints described by,

$$
P_{t}\left(C_{t}+X_{t}\right)+\mathbb{E}_{t}\left[M_{t, t+1} B_{t+1}\right] \leq B_{t}+W_{t} L_{t}+Z_{t} K_{t}
$$

and the law of motion for physical capital,

$$
K_{t+1}=(1-\delta) K_{t}+V_{t} \Phi\left(X_{t}, X_{t-1}, K_{t}\right) X_{t}
$$

where $B_{t+1}$ is the nominal payoff in period $t+1$ of the portfolio held at the end of period $t$. The portfolio includes a proportional share on the nominal profits generated by the domestic firms, since sole ownership of the domestic firms rests in the hands of the domestic households. $M_{t, t+1}$ is the stochastic discount factor (SDF) for one-period ahead nominal payoffs relevant to the domestic household.

Money plays the role of a unit of account only. $W_{t}$ is the domestic nominal wage, $P_{t}$ is the domestic consumption price index (CPI), and $Z_{t}$ defines the nominal return on capital. Moreover, $X_{t}$ is domestic real investment, $K_{t}$ stands for domestic physical capital (or capital services) in real terms ${ }^{1}$, and $V_{t}$ is an investment-specific shock as in Greenwood, et al. (1988). The foreign households maximize their lifetime utility subject to an analogous sequence of budget constraints and a law of motion for capital.

Besides investigating the role of investment-specific shocks to the law of motion in (3), we also assume that capital accumulation is subject to adjustment costs $\Phi(\cdot)$. We adopt the investment adjustment cost (IAC) function used by Christiano, et al. (2005) and Groth and Kahn (2007) as our benchmark. The IAC function takes the following form ${ }^{2}$,

$$
\Phi\left(\frac{X_{t}}{X_{t-1}}\right)=1-\frac{1}{2} \kappa \frac{\left(\frac{X_{t}}{X_{t-1}}-1\right)^{2}}{\frac{X_{t}}{X_{t-1}}},
$$

where $\frac{X_{t}}{X_{t-1}}$ denotes the gross investment growth rate. In steady state, the investment adjustment costs dissipate, investment is constant, and the investment-to-capital ratio is equal to the depreciation rate as posited in the standard neoclassical model. The same adjustment cost formula applies to the foreign household's problem.

Aggregation Rules and the Price Indexes. We assume that investment, like consumption, is a composite index of domestic and imported foreign varieties ${ }^{3}$. The home and foreign consumption bundles of the

\footnotetext{
${ }^{1}$ The distinction between physical capital and capital services only becomes relevant when we introduce differences in the capital utilization rate. Until then, we use both concepts interchangeably.

${ }^{2}$ Among the properties of this adjustment cost function that are relevant for us, we note that in steady state $\Phi(1)=1$, $\Phi^{\prime}(1)=0$, and $\Phi^{\prime \prime}(1)=-\kappa$. For more details, see the companion working paper (Martínez-García and Søndergaard, 2008).

${ }^{3}$ Aggregate investment goods can only be used by local firms after aggregation. However, local and foreign varieties of goods can be traded internationally for either consumption or investment purposes.
} 
domestic household, $C_{t}^{H}$ and $C_{t}^{F}$, as well as the investment bundles, $X_{t}^{H}$ and $X_{t}^{F}$, are aggregated by means of a CES preference index as,

$$
\begin{aligned}
C_{t}^{H} & =\left[\int_{0}^{1} C_{t}(h)^{\frac{\theta-1}{\theta}} d h\right]^{\frac{\theta}{\theta-1}}, C_{t}^{F}=\left[\int_{0}^{1} C_{t}(f)^{\frac{\theta-1}{\theta}} d f\right]^{\frac{\theta}{\theta-1}} \\
X_{t}^{H} & =\left[\int_{0}^{1} X_{t}(h)^{\frac{\theta-1}{\theta}} d h\right]^{\frac{\theta}{\theta-1}}, X_{t}^{F}=\left[\int_{0}^{1} X_{t}(f)^{\frac{\theta-1}{\theta}} d f\right]^{\frac{\theta}{\theta-1}}
\end{aligned}
$$

while domestic aggregate consumption and investment, $C_{t}$ and $X_{t}$, are defined with another CES preference index as,

$$
\begin{aligned}
& C_{t}=\left[\phi_{H}^{\frac{1}{\eta}}\left(C_{t}^{H}\right)^{\frac{\eta-1}{\eta}}+\phi_{F}^{\frac{1}{\eta}}\left(C_{t}^{F}\right)^{\frac{\eta-1}{\eta}}\right]^{\frac{\eta}{\eta-1}}, \\
& X_{t}=\left[\phi_{H}^{\frac{1}{\eta}}\left(X_{t}^{H}\right)^{\frac{\eta-1}{\eta}}+\phi_{F}^{\frac{1}{\eta}}\left(X_{t}^{F}\right)^{\frac{\eta-1}{\eta}}\right]^{\frac{\eta}{\eta-1}} .
\end{aligned}
$$

The elasticity of substitution across varieties produced within a country is $\theta>1$, and the elasticity of intratemporal substitution between the home and foreign bundles of varieties is $\eta>0$. The share of the home goods in the domestic aggregator is $\phi_{H}$, while the share of foreign goods is $\phi_{F}$. We assume the shares are homogeneous, i.e. $\phi_{H}+\phi_{F}=1$. Similarly, we define the aggregators for the foreign household. We introduce home bias in preferences (e.g., Warnock, 2003), as well as in the composition of investment, by requiring the shares to satisfy that $\phi_{H}^{*}=\phi_{F}$ and $\phi_{F}^{*}=\phi_{H}$.

The symmetry of the aggregators implies that the relative price between consumption and investment goods is one, as implied by equation (2). Given standard results on functional separability, the indexes which correspond to our specification of aggregators for the CPIs are,

$$
P_{t}=\left[\phi_{H}\left(P_{t}^{H}\right)^{1-\eta}+\phi_{F}\left(P_{t}^{F}\right)^{1-\eta}\right]^{\frac{1}{1-\eta}},
$$

and,

$$
P_{t}^{H}=\left[\int_{0}^{1} P_{t}(h)^{1-\theta} d h\right]^{\frac{1}{1-\theta}}, P_{t}^{F}=\left[\int_{0}^{1} P_{t}(f)^{1-\theta} d f\right]^{\frac{1}{1-\theta}},
$$

where $P_{t}^{H}$ and $P_{t}^{F}$ are the price sub-indexes for the home- and foreign-produced bundle of goods in units of the home currency. Similarly for the foreign CPI, $P_{t}^{*}$, and the foreign price sub-indexes, $P_{t}^{H *}$ and $P_{t}^{F *}$. We define the real exchange rate as,

$$
R S_{t} \equiv \frac{S_{t} P_{t}^{*}}{P_{t}}
$$

where $S_{t}$ denotes the nominal exchange rate.

Consumption, Savings and Investment. Aggregate consumption in each country evolves according to a pair of standard Euler equations,

$$
\begin{aligned}
\widehat{c}_{t} & \approx \mathbb{E}_{t}\left[\widehat{c}_{t+1}\right]-\sigma\left(\hat{i}_{t}-\mathbb{E}_{t}\left[\widehat{\pi}_{t+1}\right]\right), \\
\widehat{c}_{t}^{*} & \approx \mathbb{E}_{t}\left[\widehat{c}_{t+1}^{*}\right]-\sigma\left(\widehat{i}_{t}^{*}-\mathbb{E}_{t}\left[\widehat{\pi}_{t+1}^{*}\right]\right),
\end{aligned}
$$


while the perfect international risk-sharing condition implies that,

$$
\widehat{c}_{t}-\widehat{c}_{t}^{*} \approx \sigma \widehat{r s}_{t} .
$$

Equations (12) - (14) are well-known in the literature. The intertemporal elasticity of substitution, $\sigma$, regulates the sensitivity of the consumption path to real interest rates and to the real exchange rate. Equation (14), in particular, establishes a positive relationship between the real exchange rate and relative consumption across countries. Consequently, domestic consumption becomes relatively high whenever it is relatively 'cheap'.

Under the investment adjustment cost function (IAC), capital accumulation evolves according to the same law of motion,

$$
\begin{aligned}
& \widehat{k}_{t+1} \approx(1-\delta) \widehat{k}_{t}+\delta\left(\widehat{x}_{t}+\widehat{v}_{t}\right), \\
& \widehat{k}_{t+1}^{*} \approx(1-\delta) \widehat{k}_{t}^{*}+\delta\left(\widehat{x}_{t}^{*}+\widehat{v}_{t}^{*}\right),
\end{aligned}
$$

where $\widehat{k}_{t}$ and $\widehat{k}_{t}^{*}$ denote physical capital, $\widehat{x}_{t}$ and $\widehat{x}_{t}^{*}$ stand for investment, and $\widehat{v}_{t}$ and $\widehat{v}_{t}^{*}$ are the investmentspecific shocks. Moreover, the household's optimal asset pricing and investment decisions imply the following pair of equations in the home country,

$$
\begin{aligned}
\widehat{q}_{t} & \approx(1-\delta) \beta \mathbb{E}_{t}\left[\widehat{q}_{t+1}\right]+\left[(1-(1-\delta) \beta) \mathbb{E}_{t}\left(\widehat{r}_{t+1}^{z}\right)-\left(\widehat{i}_{t}-\mathbb{E}_{t}\left[\widehat{\pi}_{t+1}\right]\right)\right], \\
\widehat{x}_{t} & \approx \frac{1}{1+\beta} \widehat{x}_{t-1}+\frac{\beta}{1+\beta} \mathbb{E}_{t}\left[\widehat{x}_{t+1}\right]+\frac{1}{\kappa(1+\beta)}\left(\widehat{q}_{t}+\widehat{v}_{t}\right),
\end{aligned}
$$

and the analogous pair for the foreign country,

$$
\begin{aligned}
& \widehat{q}_{t}^{*} \approx(1-\delta) \beta \mathbb{E}_{t}\left[\widehat{q}_{t+1}^{*}\right]+\left[(1-(1-\delta) \beta) \mathbb{E}_{t}\left(\widehat{r}_{t+1}^{z *}\right)-\left(\hat{i}_{t}^{*}-\mathbb{E}_{t}\left[\widehat{\pi}_{t+1}^{*}\right]\right)\right], \\
& \widehat{x}_{t}^{*} \approx \frac{1}{1+\beta} \widehat{x}_{t-1}^{*}+\frac{\beta}{1+\beta} \mathbb{E}_{t}\left[\widehat{x}_{t+1}^{*}\right]+\frac{1}{\kappa(1+\beta)}\left(\widehat{q}_{t}^{*}+\widehat{v}_{t}^{*}\right),
\end{aligned}
$$

where $\widehat{q}_{t}$ and $\widehat{q}_{t}^{*}$ are the real shadow prices of an additional unit of investment (or Tobin's q), and $\widehat{r}_{t+1}^{z} \equiv$ $\widehat{z}_{t+1}-\widehat{p}_{t+1}$ and $\widehat{r}_{t+1}^{z *} \equiv \widehat{z}_{t+1}^{*}-\widehat{p}_{t+1}^{*}$ denote the real returns on capital. The investment-specific shocks $\widehat{v}_{t}$ and $\widehat{v}_{t}^{*}$ follow $A R(1)$ processes of the form,

$$
\begin{aligned}
\widehat{v}_{t} & =\rho_{v} \widehat{v}_{t-1}+\widehat{\varepsilon}_{t}^{v},\left|\rho_{v}\right|<1, \\
\widehat{v}_{t}^{*} & =\rho_{v} \widehat{v}_{t-1}^{*}+\widehat{\varepsilon}_{t}^{v *},\left|\rho_{v}\right|<1,
\end{aligned}
$$

where $\widehat{\varepsilon}_{t}^{v}$ and $\widehat{\varepsilon}_{t}^{v *}$ are zero mean, and normally-distributed innovations.

The asset pricing equations in (17) and (19) can be interpreted as a pair of financial arbitrage equations between real interest rates and real returns on capital. The parameter $\kappa$ regulates the degree of concavity of the IAC function around the steady state. It directly affects the sensitivity of investment to either investment-specific shocks or fluctuations in Tobin's q through the investment equations in (18) and (20). The investment equations introduce an element of inertia in investment captured by the lagged term, but also ensure that investment becomes forward-looking. Choosing the level of investment today sets the base for 
investment growth tomorrow and, therefore, affects next period's adjustment costs. Under this adjustment cost specification, the investment response to the shadow value of capital services (Tobin's q) may not be instantaneous.

\subsection{The Price-Setting Problem under Sticky Prices}

There is a continuum of firms located in the interval $[0,1]$ in each country. Each firm produces a differentiated, tradable good, supplies the home and foreign market, and sets prices in the local currency (henceforth, LCP pricing). Re-selling is infeasible across markets and, furthermore, each firm enjoys monopolistic power in its own variety. We introduce nominal rigidities à la Calvo (1983). With probability $\alpha \in(0,1)$ in each period, the firm maintains its previous period prices in both markets unchanged. However, with probability $(1-\alpha)$, the firm optimally resets its prices.

We assume that production is based on a Cobb-Douglas technology, i.e. for every firm $h \in[0,1]$,

$$
Y_{t}(h)=A_{t}\left(K_{t}(h)\right)^{1-\psi}\left(L_{t}(h)\right)^{\psi},
$$

where $A_{t}$ is an aggregate productivity shock in the home country. The labor share in the production function is pinned down by $\psi \in(0,1)$, while (23) reduces to the linear in labor case if $\psi=1$. An identical technology is used by foreign firms, but subject to a foreign-specific aggregate productivity shock $A_{t}^{*}$.

Solving the cost-minimization problem of each individual domestic firm yields an efficiency condition linking the capital-to-labor ratio to the factor price ratio as follows,

$$
\frac{K_{t}(h)}{L_{t}(h)}=\frac{1-\psi}{\psi} \frac{W_{t}}{Z_{t}}
$$

for all $h \in[0,1]$, as well as a characterization for the domestic nominal marginal costs,

$$
M C_{t}=\frac{1}{A_{t}} \frac{1}{\psi^{\psi}(1-\psi)^{1-\psi}}\left(W_{t}\right)^{\psi}\left(Z_{t}\right)^{1-\psi}
$$

Both factors, labor and capital, are homogenous within a country and immobile across borders. Factor markets are also perfectly competitive. Therefore, wages and the returns on capital equalize in each country (but not necessarily across countries), as implied in (24) and (25).

Since the production function is of constant returns to scale, all local firms choose the same capital-tolabor ratio and confront the same marginal costs even though they may end up producing different amounts. An analogous efficiency condition and nominal marginal cost function can be derived for the foreign firms.

The Optimal Pricing Problem. A re-optimizing domestic firm $h$ chooses a domestic and a foreign price, $\widetilde{P}_{t}(h)$ and $\widetilde{P}_{t}^{*}(h)$, to maximize the expected discounted value of its net profits,

$\sum_{\tau=0}^{\infty} \mathbb{E}_{t}\left\{\alpha^{\tau} M_{t, t+\tau}\left[\left(\widetilde{C}_{t, t+\tau}(h)+\widetilde{X}_{t, t+\tau}(h)\right)\left(\widetilde{P}_{t}(h)-M C_{t+\tau}\right)+\left(\widetilde{C}_{t, t+\tau}^{*}(h)+\widetilde{X}_{t, t+\tau}^{*}(h)\right)\left(S_{t+\tau} \widetilde{P}_{t}^{*}(h)-M C_{t+\tau}\right)\right]\right\}$ 
where $M_{t, t+\tau} \equiv \beta^{\tau}\left(\frac{C_{t+\tau}}{C_{t}}\right)^{-\sigma^{-1}} \frac{P_{t}}{P_{t+\tau}}$ is the SDF for $\tau$-periods ahead nominal payoffs corresponding to the domestic household, subject to a pair of demand constraints in each goods market,

$$
\begin{aligned}
\widetilde{C}_{t, t+\tau}(h)+\widetilde{X}_{t, t+\tau}(h) & =\left(\frac{\widetilde{P}_{t}(h)}{P_{t+\tau}^{H}}\right)^{-\theta}\left(C_{t+\tau}^{H}+X_{t+\tau}^{H}\right), \\
\widetilde{C}_{t, t+\tau}^{*}(h)+\widetilde{X}_{t, t+\tau}^{*}(h) & =\left(\frac{\widetilde{P}_{t}^{*}(h)}{P_{t+\tau}^{H *}}\right)^{-\theta}\left(C_{t+\tau}^{H *}+X_{t+\tau}^{H *}\right),
\end{aligned}
$$

where $\widetilde{C}_{t, t+\tau}(h)$ and $\widetilde{C}_{t, t+\tau}^{*}(h)$ indicate the consumption demand for any variety $h \in[0,1]$ at home and abroad respectively, given that prices $\widetilde{P}_{t}(h)$ and $\widetilde{P}_{t}^{*}(h)$ remain unchanged between time $t$ and $t+\tau$. Similarly, $\widetilde{X}_{t, t+\tau}(h)$ and $\widetilde{X}_{t, t+\tau}^{*}(h)$ indicate the household's investment demand. The problem is solved under the implicit assumption that firms must supply the domestic and foreign markets with as much of the consumption-investment good as it is demanded at the current prices (rationing is not allowed). We derive the demand for variety $h$ in the home and foreign markets in the companion working paper (Martínez-García and Søndergaard, 2008).

The problem of the re-optimizing foreign firm $f$ is to maximize the expected discounted value of its net profits subject to a similar pair of demand constraints.

Pricing Dynamics. The efficiency conditions that relate the capital-to-labor ratio to the factor price ratio in each country, as described by equations (24) and its foreign counterpart, can be summarized as,

$$
\begin{aligned}
\widehat{r}_{t}^{z} & \approx \frac{1}{\sigma} \widehat{c}_{t}+\frac{1+\varphi}{\psi} \widehat{y}_{t}-\left(\frac{1+(1-\psi) \varphi}{\psi}\right) \widehat{k}_{t}-\frac{1+\varphi}{\psi} \widehat{a}_{t} \\
\widehat{r}_{t}^{z *} & \approx \frac{1}{\sigma} \widehat{c}_{t}^{*}+\frac{1+\varphi}{\psi} \widehat{y}_{t}^{*}-\left(\frac{1+(1-\psi) \varphi}{\psi}\right) \widehat{k}_{t}^{*}-\frac{1+\varphi}{\psi} \widehat{a}_{t}^{*}
\end{aligned}
$$

which already substitute out both labor and wages. Households equate the marginal rate of substitution between consumption and labor to real wages. The Cobb-Douglas technology allows us to substitute out labor in the expression for real wages, and to link the capital-to-labor ratio to productivity and the capitalto-output ratio. Equations (29) and (30) are the result of re-arranging the firms' efficiency conditions along these lines, so that we can express the real return on capital as proportional to the real wages and the capitalto-labor ratio. Total output supply is obtained by aggregating the Cobb-Douglas production function over all local firms and log-linearizing, i.e.

$$
\begin{aligned}
\widehat{y}_{t} & \approx \widehat{a}_{t}+(1-\psi) \widehat{k}_{t}+\psi \widehat{l}_{t}, \\
\widehat{y}_{t}^{*} & \approx \widehat{a}_{t}^{*}+(1-\psi) \widehat{k}_{t}^{*}+\psi \widehat{l}_{t}^{*} .
\end{aligned}
$$

The productivity shocks $\widehat{a}_{t}$ and $\widehat{a}_{t}^{*}$ follow $A R(1)$ processes of the form,

$$
\begin{aligned}
\widehat{a}_{t} & =\rho_{a} \widehat{a}_{t-1}+\widehat{\varepsilon}_{t}^{a},\left|\rho_{a}\right|<1, \\
\widehat{a}_{t}^{*} & =\rho_{a} \widehat{a}_{t-1}^{*}+\widehat{\varepsilon}_{t}^{a *},\left|\rho_{a}\right|<1,
\end{aligned}
$$

where $\widehat{\varepsilon}_{t}^{a}$ and $\widehat{\varepsilon}_{t}^{a *}$ are zero mean, and normally-distributed innovations. 
Total output demand can be approximated as,

$$
\begin{aligned}
\widehat{y}_{t} & \approx \eta \widehat{t}_{t}^{W}+\left(1-\gamma_{x}\right) \widehat{c}_{t}^{W}+\gamma_{x} \widehat{x}_{t}^{W}, \\
\widehat{y}_{t}^{*} & \approx-\eta \widehat{t}_{t}^{W}+\left(1-\gamma_{x}\right) \widehat{c}_{t}^{W *}+\gamma_{x} \widehat{x}_{t}^{W *},
\end{aligned}
$$

where the superscripts $W$ and $W^{*}$ denote the following weighted averages for consumption, $\widehat{c}_{t}^{W} \equiv \phi_{H} \widehat{c}_{t}+\phi_{F} \widehat{c}_{t}^{*}$ and $\widehat{c}_{t}^{W *} \equiv \phi_{F} \widehat{c}_{t}+\phi_{H} \widehat{c}_{t}^{*}$. Similarly, for investment and for other price indexes. We define world terms of trade as $\widehat{t}_{t}^{W} \equiv \widehat{p}_{t}^{F, W *}-\widehat{p}_{t}^{W *}$, implying that an increase in $\widehat{t}_{t}^{W}$ shifts consumption and investment spending away from the foreign goods and into the domestic goods.

The inflation dynamics in the model can be derived as follows,

$$
\begin{aligned}
& \widehat{\pi}_{t} \approx \beta \mathbb{E}_{t}\left(\widehat{\pi}_{t+1}\right)+ \\
& +\left(\frac{(1-\alpha)(1-\alpha \beta)}{\alpha}\right)\left[\begin{array}{c}
\left(\sigma^{-1}+\left(1-\gamma_{x}\right) \varphi \omega\right)\left[\phi_{H} \widehat{c}_{t}^{W}+\phi_{F} \widehat{c}_{t}^{W *}\right]+\gamma_{x} \varphi \omega\left[\phi_{H} \widehat{x}_{t}^{W}+\phi_{F} \widehat{x}_{t}^{W *}\right]+ \\
+2 \phi_{H} \phi_{F} \widehat{r s}_{t}+\left(\phi_{H}-\phi_{F}\right) \eta \varphi \omega \hat{t}_{t}^{W}- \\
-\left(\frac{(1-\psi)(1+\varphi)}{\psi}\right) \widehat{k}_{t}^{W}-\left(\frac{1+\varphi}{\psi}\right)\left[\phi_{H} \widehat{a}_{t}+\phi_{F} \widehat{a}_{t}^{*}\right]
\end{array}\right], \\
& \widehat{\pi}_{t}^{*} \approx \beta \mathbb{E}_{t}\left(\widehat{\pi}_{t+1}^{*}\right)+ \\
& +\left(\frac{(1-\alpha)(1-\alpha \beta)}{\alpha}\right)\left[\begin{array}{c}
\left(\sigma^{-1}+\left(1-\gamma_{x}\right) \varphi \omega\right)\left[\phi_{F} \widehat{c}_{t}^{W}+\phi_{H} \widehat{c}_{t}^{W *}\right]+\gamma_{x} \varphi \omega\left[\phi_{F} \widehat{x}_{t}^{W}+\phi_{H} \widehat{x}_{t}^{W *}\right]+ \\
-2 \phi_{F} \phi_{H} \widehat{r s s}_{t}-\left(\phi_{H}-\phi_{F}\right) \eta \varphi \omega \widehat{t}_{t}^{W}- \\
-\left(\frac{(1-\psi)(1+\varphi)}{\psi}\right) \widehat{k}_{t}^{W *}-\left(\frac{1+\varphi}{\psi}\right)\left[\phi_{F} \widehat{a}_{t}+\phi_{H} \widehat{a}_{t}^{*}\right]
\end{array}\right],
\end{aligned}
$$

where $\omega \equiv\left(\frac{\varphi \psi^{2}+(1-\psi)(1+\varphi)^{2}}{\varphi \psi+(1-\psi) \psi \varphi^{2}}\right)$ is a composite parameter, and the investment share in steady state is given by $\gamma_{x} \equiv(1-\psi) \delta\left[\left(\frac{\theta}{\theta-1}\right)\left(\beta^{-1}-(1-\delta)\right)\right]^{-1}$. This characterization requires us to include an additional equation to pin down the world terms of trade, $\widehat{t}_{t}^{W}$, i.e.

$$
\Delta \widehat{t}_{t}^{W}-\beta \mathbb{E}_{t}\left(\Delta \widehat{t}_{t+1}^{W}\right)+\left(\frac{(1-\alpha)(1-\alpha \beta)}{\alpha}\right) \widehat{t}_{t}^{W} \approx \frac{\phi_{H} \phi_{F}}{\phi_{H}-\phi_{F}}\left[\left(\frac{(1-\alpha)(1-\alpha \beta)}{\alpha}\right) \widehat{r s}_{t}-\widehat{\pi}_{t}^{R}+\beta \mathbb{E}_{t}\left(\widehat{\pi}_{t+1}^{R}\right)\right] .
$$

Changes in world terms of trade are defined as $\Delta \widehat{t}_{t}^{W} \equiv \widehat{t}_{t}^{W}-\widehat{t}_{t-1}^{W}$, and the relative inflation as $\widehat{\pi}_{t}^{R} \equiv \widehat{\pi}_{t}-\widehat{\pi}_{t}^{*}$. Equation (39) is necessary because the relative price effects on inflation cannot be fully summarized by the real exchange rate, except in the special case where there is no home bias (i.e. $\phi_{H}=\phi_{F}$ ). Moreover, they are also necessary to determine the total output demand in $(35)-(36)^{4}$.

The first three terms inside the brackets in (37) - (38) reveal the effects of aggregate demand for consumption and investment. Adding capital requires firms to produce not only to satisfy consumption demand, but also investment demand and, naturally, that drives factor prices and inflation up. However, the sensitivity of the real marginal cost to different demand pressures varies as a function of the intertemporal elasticity of substitution, $\sigma$, the inverse of the Frisch labor supply elasticity, $\varphi$, the labor share, $\psi$, and also the investment share in steady state, $\gamma_{x}$.

The next two terms reflect the impact of expenditure-switching across countries through relative price adjustments on inflation. Real exchange rates do part of the adjustment in this model, but they are not the

\footnotetext{
${ }^{4}$ If we take consumption to be the target of monetary policy, as Steinsson (2008) does, and assume no home bias, an equation for world terms of trade is no longer necessary to close the model.
} 
only relative price to do so under home bias (i.e., if $\phi_{H} \neq \phi_{F}$ ). The world terms of trade contributes to explain changes in the demand for home- and foreign-produced goods which cannot be accounted by the real exchange rate. However, real exchange rates and world terms of trade are tied together in equation (39). The remaining two terms in (37) - (38) have to do with the effect of real shocks on the real marginal cost, and the role of the efficiency conditions ${ }^{5}$.

\subsection{Monetary Policy and Trade Patterns}

The Taylor rule is often viewed as the trademark of modern monetary policy. We consider policy rules for the short-term nominal interest rate of the type proposed by Taylor $(1993)^{6}$,

$$
\begin{aligned}
\hat{i}_{t} & =\rho_{i} \hat{i}_{t-1}+\left(1-\rho_{i}\right)\left[\psi_{\pi} \widehat{\pi}_{t}+\psi_{y} \widehat{y}_{t}\right]+\widehat{m}_{t}, \\
\widehat{i}_{t}^{*} & =\rho_{i} \widehat{i}_{t-1}^{*}+\left(1-\rho_{i}\right)\left[\psi_{\pi} \widehat{\pi}_{t}^{*}+\psi_{y} \widehat{y}_{t}^{*}\right]+\widehat{m}_{t}^{*},
\end{aligned}
$$

where $\widehat{m}_{t}$ and $\widehat{m}_{t}^{*}$ define the monetary shocks, and $\widehat{i}_{t}$ and $\widehat{i}_{t}^{*}$ are the corresponding monetary policy instruments. Also, $\widehat{\pi}_{t} \equiv \widehat{p}_{t}-\widehat{p}_{t-1}$ and $\widehat{\pi}_{t}^{*} \equiv \widehat{p}_{t}^{*}-\widehat{p}_{t-1}^{*}$ are the (gross) CPI inflation rates, and $\widehat{y}_{t}$ and $\widehat{y}_{t}^{*}$ denote the aggregate output.

The policy rules reflect the assumption that monetary authorities face a trade-off between inflation and output. In line with most of the literature, we assume that monetary authorities smooth changes in the actual short-term nominal interest rates, $\widehat{i}_{t}$ and $\hat{i}_{t}^{*}$. But a discretionary component to monetary policy is still present. Several interpretations can be given to the monetary shocks. They may reflect the central bank's failure to keep the interest rate at the level prescribed by the rule, or they might capture deliberate decisions to deviate transitorily from a systematic rule (see, e.g., Clarida, et al., 1998, 2000). It may even capture random shifts in the output potential of the economy, if the central bank targets a measure of output gap rather than output itself. Hence, $\widehat{m}_{t}$ and $\widehat{m}_{t}^{*}$ are more than discretionary policy shocks. Keeping that in mind, the monetary shocks $\widehat{m}_{t}$ and $\widehat{m}_{t}^{*}$ are modelled as exogenous $A R(1)$ processes of the form,

$$
\begin{aligned}
& \widehat{m}_{t}=\rho_{m} \widehat{m}_{t-1}+\widehat{\varepsilon}_{t}^{m},\left|\rho_{m}\right|<1, \\
& \widehat{m}_{t}^{*}=\rho_{m} \widehat{m}_{t-1}^{*}+\widehat{\varepsilon}_{t}^{m *},\left|\rho_{m}\right|<1,
\end{aligned}
$$

where $\widehat{\varepsilon}_{t}^{m}$ and $\widehat{\varepsilon}_{t}^{m *}$ are zero mean, and normally-distributed innovations.

Real Imports, Real Exports, and the Net Exports Share. In a two-country model, it suffices to determine the trade patterns from the perspective of the domestic country. The equations for domestic real

\footnotetext{
${ }^{5}$ The evolution of relative factor prices, which in our model is the evolution of wages relative to the rental rate of capital, would determine the willingness of firms to become more or less capital-intensive. Capital appears in the marginal cost structure to account, at least partially, for the effeciency gains in the factor allocation.

${ }^{6}$ Steinsson (2008) experiments with a rule that targets consumption rather than output. In a model without capital, the difference between output and consumption is given by net exports.
} 
exports and real imports can be log-linearized as,

$$
\begin{aligned}
& \widehat{\exp }_{t} \approx \eta \frac{\phi_{H}}{\phi_{F}} \widehat{t}_{t}^{W}-\eta \phi_{H}\left(\widehat{p}_{t}^{F, R}-\widehat{p}_{t}^{R}\right)+\left(1-\gamma_{x}\right) \widehat{c}_{t}^{*}+\gamma_{x} \widehat{x}_{t}^{*} \\
& \widehat{i m p}_{t} \approx-\eta \widehat{t}_{t}^{W}-\eta \phi_{H}\left(\widehat{p}_{t}^{F, R}-\widehat{p}_{t}^{R}\right)+\left(1-\gamma_{x}\right) \widehat{c}_{t}+\gamma_{x} \widehat{x}_{t} .
\end{aligned}
$$

In order to determine the evolution of both imports and exports, we need to add an additional equation from the pricing dynamics of the firms, i.e.

$$
\widehat{\pi}_{t}^{F, R}-\beta \mathbb{E}_{t}\left(\widehat{\pi}_{t+1}^{F, R}\right)+\left(\frac{(1-\alpha)(1-\beta \alpha)}{\alpha}\right)\left(\widehat{p}_{t}^{F, R}-\widehat{p}_{t}^{R}\right) \approx\left(\frac{(1-\alpha)(1-\beta \alpha)}{\alpha}\right) \widehat{r s}_{t},
$$

where $\widehat{\pi}_{t}^{F, R} \equiv \widehat{p}_{t}^{F, R}-\widehat{p}_{t-1}^{F, R}$ and $\widehat{p}_{t}^{F, R} \equiv \widehat{p}_{t}^{F}-\widehat{p}_{t}^{F *}$ represent relative price on foreign goods, while $\widehat{p}_{t}^{R} \equiv \widehat{p}_{t}-\widehat{p}_{t}^{*}$ is the relative CPI. These three equations indicate that the strength of the demand for consumption and investment purposes has a major impact on both exports and imports. They also tells us that exports and imports depend on world terms of trade, $\widehat{t}_{t}^{W}$, and indirectly on the real exchange rate, $\widehat{r}_{t}$, and the relative CPI, $\widehat{p}_{t}^{R}$. The sensitivity to world terms of trade differs between exports and imports, reflecting the effect of the home bias assumption.

Let us denote the deviation of the share of net exports over GDP from its steady state as $\widehat{t b}_{t}$. Then, the trade balance is easily computed as the difference between domestic output and domestic consumption plus investment in real terms (the domestic absorption) (see, e.g., Galí and Monacelli, 2005), i.e.

$$
\widehat{t}_{t} \equiv \widehat{y}_{t}-\left(1-\gamma_{x}\right) \widehat{c}_{t}-\gamma_{x} \widehat{x}_{t}
$$

Using the formula for total output demand in (35), we derive the following characterization for the share of real net exports ${ }^{7}$,

$$
\widehat{t b}_{t} \approx \eta \widehat{t}_{t}^{W}-\left(1-\gamma_{x}\right) \phi_{F}\left(\widehat{c}_{t}-\widehat{c}_{t}^{*}\right)-\gamma_{x} \phi_{F}\left(\widehat{x}_{t}-\widehat{x}_{t}^{*}\right)=\phi_{F}\left(\widehat{\exp }_{t}-\widehat{i m p}_{t}\right)
$$

where the second equality follows from the perfect international risk-sharing condition in (14). All relative price effects on the trade balance are subsumed in our measure of world terms of trade, $\widehat{t}_{t}^{W}$.

\subsection{The Benchmark and Other Specifications}

The core of the model consists of three blocks of equations. The first block has two Euler equations (equations (12) - (13)) and the perfect international risk-sharing condition (equation (14)) to characterize the consumption-savings decisions of households. It has a pair of asset pricing equations for Tobin's q coupled with two investment equations (equations (17) - (20)) for the capital-investment decisions. We also add two more equations for the law of motion of capital in the domestic and foreign countries (equations (15) - (16)).

The second block adds three more equations to define the dynamics of inflation at home and abroad as well as a measure of world terms of trade (equations (37) - (39)). This block also includes a pair of efficiency conditions that constraint the real returns on capital (equations (29) - (30)), and two more equations to

\footnotetext{
${ }^{7}$ In steady state, the real trade balance is zero by assumption. Nonetheless, exchanges do occur between the two countries and the parameter $\phi_{F}$ represents the steady state share of imports for consumption and investment purposes relative to output.
} 
describe the total output demand in both countries (equations (35) - (36)). The third and final block summarizes the role of the monetary authorities with a pair of monetary policy rules (equations (40) - (41)). We complete the core of the model by assuming that all six exogenous shocks, i.e. $\widehat{a}_{t}, \widehat{a}_{t}^{*}, \widehat{m}_{t}, \widehat{m}_{t}^{*}, \widehat{v}_{t}$ and $\widehat{v}_{t}^{*}$, follow $A R(1)$ processes.

The equations described so far constitute a system of 18 equations and 18 endogenous variables, not counting definitions. Given initial conditions and the shock processes, this system constitutes a fully specified rational expectations model. The model is augmented with the linearized production functions (equations $(31)-(32))$ to pin down employment, and the real share of net exports of the home country (equation (47)). We also complement the core with three more equations to determine domestic real exports and real imports (equations (44) - (46)). These 6 additional equations determine 6 more endogenous variables as functions of themselves, the 6 exogenous shocks and the other 18 endogenous variables.

In order to test the robustness of our results, we also explore changes to our benchmark specification. More specifically, we investigate a model with an alternative specification for the adjustment cost function as well as a model with capital utilization rates. None of these modifications have a direct impact on the linearized production functions (equations $(31)-(32)$ ), the real share of net exports (equation (47)), real exports and real imports (equations (44) - (46)), or the monetary policy rules (equations (40)-(41)). Hence, we only review the rest of the equations in the system.

\subsubsection{Alternative Adjustment Cost Specifications}

We investigate the role of two other adjustment cost functions. The no adjustment costs (NAC) specification, i.e.

$$
\Phi\left(X_{t}, X_{t-1}, K_{t}\right)=1
$$

and the capital adjustment cost (CAC) specification (favored by CKM, 2002, and Canzoneri, et al., 2007), which takes the following form ${ }^{8}$,

$$
\Phi\left(\frac{X_{t}}{K_{t}}\right)=1-\frac{1}{2} \chi \frac{\left(\frac{X_{t}}{K_{t}}-\delta\right)^{2}}{\frac{X_{t}}{K_{t}}},
$$

where $\frac{X_{t}}{K_{t}}$ denotes the investment-to-capital (services) ratio, and $\delta$ is the depreciation rate in the law of motion for capital. In steady state, the adjustment costs dissipate in either case, investment is constant, and the investment-to-capital ratio is equal to the depreciation rate as posited in the standard neoclassical model. The same adjustment cost formula applies to the foreign household's problem.

The Euler equations and the perfect international risk-sharing condition in (12) - (14) are unaffected by these changes. Furthermore, we also find that capital accumulation evolves according to the same law of motion described in (15) - (16), for any one of the adjustment cost functions. The modification of the adjustment cost function has no direct impact the pricing equations that determine domestic and foreign inflation as well as world terms of trade (equations (37) - (39)), the efficiency conditions for the firms (equations (29) - (30)), and total output demand in both countries (equations (35) - (36)) either. Changes in the adjustment cost function, after all, only affect the investment-savings margin for households, since they are the ones making all the decisions relative to capital.

\footnotetext{
${ }^{8}$ Among the properties of this adjustment cost function that are relevant for us, we note that in steady state $\Phi(\delta)=1$, $\Phi^{\prime}(\delta)=0$, and $\Phi^{\prime \prime}(\delta)=-\frac{\chi}{\delta}$. For more details, see the companion working paper (Martínez-García and Søndergaard, 2008).
} 
Savings and Investment Decisions. Under NAC, the household's optimal asset pricing and investment decisions imply the following pair of equations in the home country,

$$
\begin{aligned}
& \widehat{q}_{t} \approx(1-\delta) \beta \mathbb{E}_{t}\left[\widehat{q}_{t+1}\right]+\left[(1-(1-\delta) \beta) \mathbb{E}_{t}\left(\widehat{r}_{t+1}^{z}\right)-\left(\widehat{i}_{t}-\mathbb{E}_{t}\left(\widehat{\pi}_{t+1}\right)\right)\right], \\
& \widehat{q}_{t} \approx-\widehat{v}_{t}
\end{aligned}
$$

and the analogous pair for the foreign country,

$$
\begin{aligned}
& \widehat{q}_{t}^{*} \approx(1-\delta) \beta \mathbb{E}_{t}\left[\widehat{q}_{t+1}^{*}\right]+\left[(1-(1-\delta) \beta) \mathbb{E}_{t}\left(\widehat{r}_{t+1}^{z *}\right)-\left(\hat{i}_{t}^{*}-\mathbb{E}_{t}\left(\widehat{\pi}_{t+1}^{*}\right)\right)\right], \\
& \widehat{q}_{t}^{*} \approx-\widehat{v}_{t}^{*} .
\end{aligned}
$$

The investment equations in (51) and (53) indicate that Tobin's q is constant (and equal to one); a wellknown result for the neoclassical model, unless there is an investment-specific shock. The asset pricing equations in (50) and (52) show that, without investment-specific shocks, real interest rates and real returns on capital must be equated through arbitrage after taking into account the 'effect' of capital depreciation.

Under CAC, the household's optimal asset pricing and investment decisions imply the following pair of equations in the home country,

$$
\begin{aligned}
\widehat{q}_{t} & \approx \beta \mathbb{E}_{t}\left[\widehat{q}_{t+1}\right]+\left[(1-(1-\delta) \beta) \mathbb{E}_{t}\left(\widehat{r}_{t+1}^{z}\right)-\left(\widehat{i}_{t}-\mathbb{E}_{t}\left(\widehat{\pi}_{t+1}\right)\right)\right] \\
\widehat{q}_{t} & \approx \chi \delta\left(\widehat{x}_{t}-\widehat{k}_{t}\right)-\widehat{v}_{t}
\end{aligned}
$$

and an analogous pair for the foreign country,

$$
\begin{aligned}
\widehat{q}_{t}^{*} & \approx \beta \mathbb{E}_{t}\left[\widehat{q}_{t+1}^{*}\right]+\left[(1-(1-\delta) \beta) \mathbb{E}_{t}\left(\widehat{r}_{t+1}^{* *}\right)-\left(\widehat{i}_{t}^{*}-\mathbb{E}_{t}\left(\widehat{\pi}_{t+1}^{*}\right)\right)\right], \\
\widehat{q}_{t}^{*} & \approx \chi \delta\left(\widehat{x}_{t}^{*}-\widehat{k}_{t}^{*}\right)-\widehat{v}_{t}^{*}
\end{aligned}
$$

where $\chi$ regulates the degree of concavity of the CAC function around the steady state. This parameter directly affects the sensitivity of investment to either investment-specific shocks or fluctuations in Tobin's $\mathrm{q}$ through the investment equations in (55) and (57). As a result, investment under the CAC specification responds immediately to movements in Tobin's q unlike in our benchmark. The asset pricing equations in (54) and (56) also put more weight on the forward-looking component than those of the NAC (equations (50) and (52)) and IAC (equations (17) and (19)) cases.

\subsubsection{Alternative Specification with Capital Utilization}

We assume now that the domestic household maximizes its lifetime utility in (1) subject to a slightly different sequence of budget constraints described by,

$$
P_{t}\left(C_{t}+X_{t}+A\left(U_{t}\right) \widetilde{K}_{t}\right)+\mathbb{E}_{t}\left[M_{t, t+1} B_{t+1}\right] \leq B_{t}+W_{t} L_{t}+Z_{t} U_{t} \widetilde{K}_{t}
$$

and the law of motion for physical capital,

$$
\widetilde{K}_{t+1}=(1-\delta) \widetilde{K}_{t}+V_{t} \Phi\left(X_{t}, X_{t-1}, K_{t}\right) X_{t}
$$


where all variables are defined as before, except for capital. Here, $\widetilde{K}_{t}$ stands for domestic physical capital, while $K_{t}$ are the capital services effectively rented to firms. Capital services, $K_{t}$, are related to physical capital, $\widetilde{K}_{t}$, according to,

$$
K_{t}=U_{t} \widetilde{K}_{t}
$$

where $U_{t}$ is the capital utilization rate as in Christiano, et al. (2005). The foreign households maximize their lifetime utility subject to an analogous sequence of budget constraints and the law of motion for capital.

We assume that households own the physical capital and also set the utilization rate that determines the real amount of capital services available to rent. The increasing and convex function, $A\left(U_{t}\right)$, denotes the cost in units of consumption goods of setting the utilization rate to $U_{t}$. We impose that $A(1)=0$ to ensure that capital utilization drops out whenever the utilization rate is fixed at one, i.e. $U_{t}=1$ for all $t$. We assume that in steady state the utilization rate is always one, i.e. $\bar{U}=1$. We denote $\lambda \equiv \frac{A^{\prime \prime}(1)}{A^{\prime}(1)}$ the elasticity of the capital utilization cost evaluated at steady state.

Consumption, Savings and Investment. Once again, the Euler equations and the perfect international risk-sharing condition in equations (12)-(14) are unaffected by these changes. However, capital accumulation evolves now from the following law of motion,

$$
\begin{aligned}
& \widehat{\widetilde{k}}_{t+1} \approx(1-\delta) \widehat{\widetilde{k}}_{t}+\delta\left(\widehat{x}_{t}+\widehat{v}_{t}\right), \\
& \widehat{\widetilde{k}}_{t+1}^{*} \approx(1-\delta) \widehat{\widetilde{k}}_{t}^{*}+\delta\left(\widehat{x}_{t}^{*}+\widehat{v}_{t}^{*}\right),
\end{aligned}
$$

where $\widehat{\widetilde{k}}_{t}$ and $\widehat{\widetilde{k}}_{t}^{*}$ denote physical capital. The law of motion in (61) and (62) is the same independently of the choice of the adjustment cost function (either NAC, CAC or IAC). Capital services, which we denote $\widehat{k}_{t}$ and $\widehat{k}_{t}^{*}$ respectively, are related to physical capital as follows,

$$
\begin{aligned}
& \widehat{k}_{t} \approx \widehat{\widetilde{k}}_{t}+\widehat{u}_{t}, \\
& \widehat{k}_{t}^{*} \approx \widehat{\widetilde{k}}_{t}^{*}+\widehat{u}_{t}^{*},
\end{aligned}
$$

where $\widehat{u}_{t}$ and $\widehat{u}_{t}^{*}$ identify the capital utilization rates. Physical capital and capital services are identical only if the capital utilization rate is kept at its steady state level, i.e. whenever $\widehat{u}_{t}=\widehat{u}_{t}^{*}=0$ for all $t$.

Under NAC and IAC, the household's optimal asset pricing and investment decisions are still those reported in equations $(50)-(53)$ and $(17)-(20)$, respectively. It is worth noticing that the capital term involved in these equations has to be interpreted now as capital services, rather than physical capital. With capital utilization we must add two more equations in either case, i.e.

$$
\begin{aligned}
& \mathbb{E}_{t}\left[\widehat{r}_{t+1}^{z}\right] \approx \lambda \mathbb{E}_{t}\left[\widehat{u}_{t+1}\right], \\
& \mathbb{E}_{t}\left[\widehat{r}_{t+1}^{z *}\right] \approx \lambda \mathbb{E}_{t}\left[\widehat{u}_{t+1}^{*}\right],
\end{aligned}
$$

to indicate how the capital utilization rate relates to returns on capital. These equations show that the expected cost of marginally increasing the utilization of capital should be commensurate to their expected returns. Under CAC, the household's optimal asset pricing and investment decisions are those reported in equations $(54)-(57)$. With capital utilization, the utilization rate also balances marginal costs and benefits, 
i.e.

$$
\begin{aligned}
& \mathbb{E}_{t}\left[\widehat{r}_{t+1}^{z}\right] \approx \mathbb{E}_{t}\left[\lambda \widehat{u}_{t+1}-\left(\frac{\delta \beta}{1-(1-\delta) \beta}\right) \widehat{q}_{t+1}\right] \\
& \mathbb{E}_{t}\left[\widehat{r}_{t+1}^{z *}\right] \approx \mathbb{E}_{t}\left[\lambda \widehat{u}_{t+1}^{*}-\left(\frac{\delta \beta}{1-(1-\delta) \beta}\right) \widehat{q}_{t+1}^{*}\right],
\end{aligned}
$$

but here the trade-off between investment and capital utilization pops-up in the determination of the utilization rates.

The Price-Setting Problem under Sticky Prices. The efficiency conditions in (29) and (30) only change conceptually because capital now refers to capital services, rather than physical capital. The total output demand in (35) and (36) has to be augmented to account for the costs of capital utilization in the model, i.e.

$$
\begin{aligned}
& \widehat{y}_{t} \approx \eta \widehat{t}_{t}^{W}+\left(1-\gamma_{x}\right) \widehat{c}_{t}^{W}+\gamma_{x} \widehat{x}_{t}^{W}+\gamma_{x}\left(\frac{1-\beta(1-\delta)}{\beta \delta}\right) \widehat{u}_{t}, \\
& \widehat{y}_{t}^{*} \approx-\eta \widehat{t}_{t}^{W}+\left(1-\gamma_{x}\right) \widehat{c}_{t}^{W *}+\gamma_{x} \widehat{x}_{t}^{W *}+\gamma_{x}\left(\frac{1-\beta(1-\delta)}{\beta \delta}\right) \widehat{u}_{t}^{*},
\end{aligned}
$$

where the superscripts $W$ and $W^{*}$ denote the same weighted averages as before. The inflation dynamics in the model can be simply extended as follows,

$$
\begin{aligned}
& \widehat{\pi}_{t} \approx \beta \mathbb{E}_{t}\left(\widehat{\pi}_{t+1}\right)+\left[\begin{array}{c}
\left(\sigma^{-1}+\left(1-\gamma_{x}\right) \varphi \omega\right)\left[\phi_{H} \widehat{c}_{t}^{W}+\phi_{F} \widehat{c}_{t}^{W *}\right]+\gamma_{x} \varphi \omega\left[\phi_{H} \widehat{x}_{t}^{W}+\phi_{F} \widehat{x}_{t}^{W *}\right]+ \\
+\gamma_{x} \varphi \omega\left(\frac{1-\beta(1-\delta)}{\beta \delta}\right)\left[\phi_{H} \widehat{u}_{t}+\phi_{F} \widehat{u}_{t}^{*}\right]+ \\
+2 \phi_{H} \phi_{F} \widehat{r s}_{t}+\left(\phi_{H}-\phi_{F}\right) \eta \varphi \omega t_{t}^{W}- \\
-\left(\frac{(1-\psi)(1+\varphi)}{\psi}\right) \widehat{k}_{t}^{W}-\left(\frac{1+\varphi}{\psi}\right)\left[\phi_{H} \widehat{a}_{t}+\phi_{F} \widehat{a}_{t}^{*}\right]
\end{array}\right], \\
& \widehat{\pi}_{t}^{*} \approx \beta \mathbb{E}_{t}\left(\widehat{\pi}_{t+1}^{*}\right)+\left[\begin{array}{c}
(1-\alpha \beta) \\
+\left(\frac{(1-\alpha)(1-\alpha \beta)}{\alpha}\right)
\end{array}\right] \\
& {\left[\begin{array}{c}
\left(\sigma^{-1}+\left(1-\gamma_{x}\right) \varphi \omega\right)\left[\phi_{F} \widehat{c}_{t}^{W}+\phi_{H} \widehat{c}_{t}^{W *}\right]+\gamma_{x} \varphi \omega\left[\phi_{F} \widehat{x}_{t}^{W}+\phi_{H} \widehat{x}_{t}^{W *}\right]+ \\
+\gamma_{x} \varphi \omega\left(\frac{1-\beta(1-\delta)}{\beta \delta}\right)\left[\phi_{F} \widehat{u}_{t}+\phi_{H} \widehat{u}_{t}^{*}\right]- \\
-2 \phi_{F} \phi_{H} \widehat{r s}_{t}-\left(\phi_{H}-\phi_{F}\right) \eta \varphi \omega t_{t}^{W}- \\
-\left(\frac{(1-\psi)(1+\varphi)}{\psi}\right) \widehat{k}_{t}^{W *}-\left(\frac{1+\varphi}{\psi}\right)\left[\phi_{F} \widehat{a}_{t}+\phi_{H} \widehat{a}_{t}^{*}\right]
\end{array}\right] .}
\end{aligned}
$$

This characterization of the Phillips curves requires us to include an additional equation to pin down the world terms of trade, $\widehat{t}_{t}^{W}$, i.e. equation (39), which remains unaffected by the addition of capital utilization.

Equations (71) - (72) have the same interpretation as (37) - (38). They differ because only capital services (not physical capital) matters for the characterization of marginal costs, and because capital utilization costs increase the demand confronted by firms, raising factor prices and inflation. Otherwise, nothing fundamental has altered the structure of pricing equations. 


\section{Model Calibration}

In this section, we describe the choice of the parameter values. Our calibration is summarized in Table 1. For comparison purposes, the parameterization of CKM (2002) and Steinsson (2008) also appears in Table 1. In order to keep our model comparable, our choice of values for the structural parameters is very similar to theirs.

\section{[Insert Table 1 about here]}

We assume that the discount factor, $\beta$, equals 0.99 which is consistent with an annual real return of $4 \%$. We set the intertemporal elasticity of substitution, $\sigma$, to $1 / 5$ as in CKM (2002) and Steinsson (2008). The inverse of the Frisch elasticity of labor supply, $\varphi$, is set to 3 which is compatible with the available micro evidence (see, e.g., Browning, et al., 1999, and Blundell and MaCurdy, 1999). This choice also brings the 'strategic complementarity of consumption' in the Phillips curve, $\sigma^{-1}+\left(1-\gamma_{x}\right) \varphi \omega$, closer to Steinsson's (2008) number.

The elasticity of substitution across varieties, $\theta$, is set to 10 . This is consistent with a price mark-up of $11 \%$ as documented in the U.S. data by Basu (1996). ${ }^{9}$ Steinsson (2008) sets the intratemporal elasticity of substitution, $\eta$, also equal to 10 . We believe this value is rather high in comparison with the usual calibrations in the international business cycle literature. For instance, Backus, et al. (1995) assume values between 0.9 and 2, while CKM (2002) select 1.5 for their sticky-price model. Empirical work by Lai and Trefler (2002) finds estimates somewhere in the middle, around 5.5. Our benchmark calibration sets this parameter to 1.5 as in CKM (2002). Obviously, a great deal of uncertainty about the true value still exists.

The home and foreign shares, $\phi_{H}$ and $\phi_{F}$, are set respectively to 0.94 and 0.06. CKM (2002) relies on these values to match the observation that U.S. imports from Europe are roughly $1.6 \%$ of GDP. Our parameterization is taken directly from theirs. As is conventional, we set the labor share, $\psi$, equal to $2 / 3$ and the depreciation rate, $\delta$, equal to 0.021 . The latter implies an annual depreciation rate of $10 \%$ which is typical for the U.S. data. The Calvo price stickiness parameter, $\alpha$, is assumed to be 0.75 . This implies that the average price duration in our model is 4 quarters, making it comparable with the degree of nominal price stickiness assumed in CKM (2002).

The parameterization of the monetary policy rule is identical to Steinsson (2008), except that our rule targets output rather than consumption. The interest rate inertia parameter, $\rho_{i}$, equals 0.85 , while the weight on the inflation target, $\psi_{\pi}$, equals 2 , and the weight on the output target, $\psi_{y}$, is 0.5 .

The Calibration of Shocks and Other Cost Parameters. We assume identical $A R(1)$ exogenous processes for the monetary, the real, and the investment-specific shocks and set the persistence of all those shocks, $\rho_{m}, \rho_{a}$ and $\rho_{v}$, equal to 0.9. This is in line with the parameterization of Steinsson (2008). In CKM (2002), the volatility of the monetary innovations is selected to match the volatility of output, and the correlation of domestic and foreign monetary innovations is calibrated to match the observed crosscorrelation of output. We adopt a similar calibration strategy and set the standard deviation of all shocks

\footnotetext{
${ }^{9} \mathrm{Up}$ to a first-order approximation, the elasticity of substitution across varieties only enters our considerations because the mark-up affects the steady state investment share (over GDP), $\gamma_{x}$. The choice of $\theta$ equal to 10 as a free parameter implies that the steady state investment share is 0.203. In Cooley and Prescott (1995), after excluding both the stock of government capital and the income that it generates, the investment share is calculated at 0.252 . Hence, our choice of the parameter $\theta$ is both consistent with empirical estimates of the mark-up and with the long-run measures of the investment share.
} 
to match the output volatility in the U.S. data (i.e., 1.54\%). In addition, we calibrate the cross-country correlation of all innovations to replicate the observed cross-correlation of U.S. and Euro-zone GDP (i.e., $0.44)$.

In the exercise where both monetary and real shocks drive the business cycle, we assume that real shock innovations are 4 times as volatile as monetary innovations. This is based on the results in Søndergaard (2004) who infers the volatility of U.S. real and monetary innovations from estimates of productivity and a Taylor rule for the U.S. We assume that the cross-country correlation of real innovations is identical to that of monetary innovations. Given these constraints, we calibrate the volatility and correlation of real innovations to match the volatility and cross-country correlation of GDP in the data.

Finally, we select the appropriate capital or investment adjustment cost parameter, either $\chi$ or $\kappa$, to ensure that investment volatility in the model is as volatile as in the data (i.e., 3.38 times as volatile as U.S. GDP in real terms $)^{10}$. In models with capacity utilization, we set the elasticity of capital utilization costs, $\lambda$, to match the value of 5.80 estimated by Justiniano, et al. (2008).

\section{Quantitative Findings ${ }^{11}$}

In this section, we examine how adding capital accumulation affects the performance of our open economy model, and ask whether a sticky-price model with pricing-to-market can generate the type of international business cycle fluctuations that can be observed in the data between the U.S. and the Euro-zone. To answer this question, we compare a model set-up with capital and investment adjustment costs (IAC) against an alternative model with linear-in-labor technologies and no capital (NoC). In Table 2, we analyze the effects of monetary shocks over the business cycle. In Tables 3, 4 and 5 we explore respectively the contribution of real shocks, investment-specific shocks and a combination of monetary and real shocks.

While our primary focus is how the model explains real exchange rate dynamics, we also report a number of relevant business cycle moments for each simulation. In particular, we make an extra effort to cross-validate the main predictions of our model by showing whether or not getting the real exchange rate right comes at the expense of worsening the model predictions along some other dimension of interest. Of particular importance, obviously, is monitoring the impact the model has on trading patterns.

We also test the robustness of our conclusions to the specification of different adjustment cost functions (see, e.g., CKM, 2002) and to the assumption of variable capital utilization rates (see, e.g., Christiano, et al., 2005).

The Features of the Data. The main features of the data are well-known from the work of CKM (2002). Real U.S. GDP has a standard deviation of $1.54 \%$, while U.S. investment and consumption are respectively 3.38 and 0.81 times as volatile as GDP. All three series are very persistent with a first-order autocorrelation around 0.85. In the data, the cross-country correlation of U.S. GDP with Euro-zone GDP is higher, at 0.44,

\footnotetext{
${ }^{10}$ We use the adjustment cost parameter to match the volatility of investment instead of the volatility of consumption as in CKM (2002). Thus, in our case, the volatility of consumption is endogenously determined (rather than chosen). This has implications for the volatility of the real exchange rate, which in turn makes the simulations easier to interpret: If the model does not generate enough consumption volatility, it is likely not to deliver the right real exchange rate volatility.

${ }^{11}$ All our simulation results have been generated using the software package Dynare (see, e.g., Juillard, 2003), while the theoretical moments are all based on Hodrick-Prescott filtered time-series.
} 
than either consumption or investment, both at 0.33. U.S. employment relative to GDP, in turn, is less volatile at $1.02 \%$, less correlated across countries at 0.29 , but more persistent at 0.92 .

One of the central puzzles in international business cycles, the PPP puzzle, arises empirically because the real exchange rate is known to be quite volatile and persistent. The standard deviation of the real exchange rate is about 5.14 times that of U.S. GDP ${ }^{12}$, and its first-order autocorrelation is close to 0.78. These moments, however, are notably hard to derive in an endogenous open-economy model, even under price-stickiness and pricing-to-market. Hence, this gives rise to the PPP puzzle.

Finally, the real exchange rate is expected to play a significant role in determining cross-country trade patterns, since international relative prices determine the size of the expenditure-switching effect. With regards to trade, we note that the real trade balance is barely 0.25 times more volatile than GDP, but real exports and imports are respectively 2.59 and 3.31 times more volatile. All export-related series are very persistent, around $0.83-0.85$. But U.S. exports and imports tend to display some differences; for instance, U.S. GDP is positively correlated with U.S. exports and imports, but the correlation with imports is twice as strong (0.82 versus 0.41$)$. U.S. GDP is also negatively correlated with net exports at -0.47 , while exports and imports are positively correlated at a low value of 0.21 . For more details on the observed trade patterns, see also Engel and Wang (2007) and Raffo (2008a).

Is Perfect International Risk-Sharing Incompatible with the Data? A general equilibrium model with complete international financial markets implies a fairly tight link between real exchange rates and relative consumption. As argued by CKM (2002), the perfect international risk-sharing condition in (14) gives rise to the Backus-Smith puzzle; that is a theoretical high positive correlation between relative consumption and the real exchange which is not consistent with the data (see Backus and Smith, 1993). The question is whether this tight link between relative prices and quantities hinders our ability to simultaneously match the volatility and persistence of output, consumption and the real exchange rate.

Given the household preferences, the connection between real exchange rate and consumption volatility can be expressed as,

$$
\frac{\operatorname{var}(\widehat{r s})}{\operatorname{var}(\widehat{y})} \cong \frac{2}{\sigma^{2}}\left[1-\operatorname{corr}\left(\widehat{c}, \widehat{c}^{*}\right)\right] \frac{\operatorname{var}(\widehat{c})}{\operatorname{var}(\widehat{y})}
$$

Similarly, the real exchange rate persistence implied by the model is tied to the persistence of consumption such that the first-order autocorrelations of both are approximately equal, i.e.

$$
\operatorname{corr}\left(\widehat{r s}, \widehat{r s}_{-1}\right) \cong \operatorname{corr}\left(\widehat{c}, \widehat{c}_{-1}\right)
$$

Hence, our model's ability to generate real exchange rate volatility hinges on whether it can generate sufficient consumption volatility and the right consumption cross-correlation; while the persistence of the real exchange rate and the persistence of consumption are like two-sides of the same coin. ${ }^{13}$

As a starting point, we ask ourselves to what extent the perfect international risk-sharing condition, as

\footnotetext{
${ }^{12}$ Our measure of RER volatility is comparable to that used by CKM (2002). Our raw measure of RER volatility is $7.94 \%$ compared to $7.91 \%$ in CKM (2002). Our GDP is slightly less volatile than CKM (2002) (1.54\% vs. 1.82\%). The main reason for the discrepancy in the ratio is that our sample period captures more of the Great Moderation era than theirs does. The implication is that relative to GDP, the volatility of the RER is 4.36 in CKM (2002) and 5.14 in our dataset. We believe the number is nonetheless relevant for the purpose of this paper.

${ }^{13}$ For more details on the derivation of equations (73) and (74), see the Appendix.
} 
it transpires in (73) and (74), is compatible with the data itself. First, we observe that the consumption first-order autocorrelation in the data is 0.87 compared with 0.78 for the real exchange rate. Second, we find that the empirical cross-country correlation of consumption and the empirical volatilities of consumption and GDP imply a model-consistent volatility for the real exchange rate relative to GDP of 4.40, compared with 5.14 in the data. ${ }^{14}$ Given our choice of preferences, and particularly our parameterization of the elasticity of substitution, perfect international risk-sharing is not outright inconsistent with the features of either consumption or the real exchange rate as observed in the data. Furthermore, we can say that if our theory is unable to match the properties of either consumption or the real exchange rate, it likely fails to match them both.

\subsection{Monetary Policy Shocks}

The first set of our experiments assumes that all exogenous disturbances are monetary policy shocks. To shed light on the relationship between capital accumulation and real exchange rate dynamics, we compare simulation results from a model with capital accumulation (IAC) with results from a model with no capital (NoC).

\subsubsection{Impulse Responses}

Figure 1 shows the impulse responses for a contractionary domestic monetary policy shock (i.e., an increase in $\widehat{\varepsilon}_{t}^{m}$ ) in our benchmark model with capital (IAC) as well as our model without capital (NoC). The qualitative effects of a monetary contraction are similar in the two models. Higher interest rates increase the cost of consuming today relative to saving for tomorrow. ${ }^{15}$ Domestic consumption and, hence, aggregate demand falls in both models.

\section{[Insert Figure 1 about here]}

How do monetary shocks affect the real exchange rate? The impulse responses in Figure 1 indicate that a contractionary monetary shock causes the domestic currency to appreciate in real terms. The intuition follows naturally from the perfect international risk-sharing condition in (14) which links the real exchange rate to domestic and foreign consumption.

Since the domestic and foreign monetary shocks are assumed to be correlated (in order to match the cross-country correlation of GDP), foreign consumption declines as well. Given that the monetary policy shock originates in the domestic economy, it triggers a greater decline in domestic consumption, $\widehat{c}_{t}$, than in foreign consumption, $\widehat{c}_{t}^{*}$. Hence, consumption becomes relatively higher in the foreign country, and the international risk-sharing condition implies that the real exchange rate, $\widehat{r}_{t}$, has to fall becoming relatively 'cheaper' (i.e., a real appreciation from the domestic point of view).

While the qualitative results are identical in models with and without capital, there are important quantitative differences. ${ }^{16}$ Figure 1 shows that the required real exchange rate appreciation is relatively

\footnotetext{
${ }^{14}$ To exactly match the real exchange rate volatility in the data we would need to reduce the elasticity of substitution from $\frac{1}{5}$ to $\frac{1}{5.84}$.

${ }^{15}$ However, without price stickiness, all monetary policy shocks would translate into inflation and have no impact on real interest rates.

${ }^{16}$ While the shape of most impulse response functions is very similar for the models with and without capital, there are significative differences on the trade patterns. Most notably, on the dynamics of domestic imports.
} 
smaller in our benchmark with capital. In this case, a contractionary monetary policy shock increases the cost of consuming today relative to saving for tomorrow through the Euler equations in (12) and (13), and households choose to postpone consumption today. It also increases the cost of capital through the asset pricing equations for Tobin's q in (54) and (56), lowering the investment demand. ${ }^{17}$ The greater volatility of investment and the attenuated spill-overs into the foreign economy ultimately forces relative prices (in particular, the real exchange rate) to play a greater role to help switch expenditure across country and equate the domestic supply to the sum of domestic and foreign demand.

Alternatively, one could simply argue that without access to physical capital, households cannot smooth consumption by dissaving in the immediate periods following a contractionary monetary policy shock. There is no intertemporal channel for them to transfer production from one period to the next. Therefore, their consumption has to fall by a larger amount relative to a set-up where they could alter their investment-savings decisions in response to that shock.

The impulse responses illustrate the persistence problem inherent in both models. The real exchange rate responds sharply in period 1 but then reverts fairly rapidly towards its steady state. From period 4 onwards, the real exchange rate dynamics are quite muted. The response of the real exchange rate to a monetary shock is not hump-shaped either, because output and inflation move in the same direction (contrary to what happens in response to a real shock) and monetary policy does not have to balance out two conflictive objectives (see, e.g., Steinsson, 2008). ${ }^{18}$ But it becomes slightly more gradual without capital, which explains why the NoC model gets a little bit more persistence than our benchmark out of a monetary shock.

\subsubsection{Theoretical Moments}

Other features of the business cycle, particularly consumption, output and investment, are as important as the real exchange rate. We realize that real exchange rates, as relative prices, influence the expenditureswitching across countries and hence the trade flows. So, we pay special attention to the implications of capital for the model's ability to replicate observed fluctuations in export and import volumes. The performance of each model is assessed by comparing the theoretical moments with the empirical business cycle statistics for the main variables of interest.

The theoretical moments from simulating our benchmark economy in response to monetary shocks are summarized in the second column of Table 2, under the header 'IAC'. For easy comparison, the third column contains the simulation results for a model with no capital accumulation, under the header of 'NoC'.

[Insert Table 2 about here]

One key result from Table 2 is that the model without capital (NoC) generates real exchange rates that are more volatile than what we observe in the data. The volatility of real exchange rates relative to output implied by this particular model is 6.44 times the volatility of output, while in the data is just 5.14 times more volatile. However, the model without capital fails to produce a sufficiently persistent real exchange

\footnotetext{
${ }^{17} \mathrm{CKM}(2000)$ point out that investment is particularly interest-sensitive in a closed economy sticky-price model written in the same spirit as ours. Our results confirm that this is also true in an open economy framework.

${ }^{18}$ The simulation results for CPI inflation and nominal interest rates are not reported but can be obtained directly from the authors upon request.
} 
rate, since the theoretical autocorrelation of the real exchange rate is 0.52 against 0.78 in the data. Not surprisingly, by the approximation in (74), consumption appears also much less persistent than in the data, 0.50 versus 0.87 .

In contrast, the benchmark model with capital (IAC) produces real exchange rates that are both less volatile at 5.13 times the volatility of output, and less persistent at 0.44 . So while both types of models appear to resolve the international pricing puzzle, they fail to account for the persistence anomaly. These findings are broadly in line with CKM (2002) and Steinsson $(2008)^{19}$. What makes the low persistence all the more puzzling is that, unlike CKM (2002), we rely on very persistent monetary shocks in an attempt to give them a better chance to match the persistence of the real exchange rate, and we also introduce further persistence through the investment equations in (18) and (20). But that is not enough to raise the autocorrelation.

The business cycle statistics for consumption illustrates why the model without capital (NoC) generates more real exchange rate volatility than our benchmark model (IAC). Consumption in the benchmark case is both less volatile and less persistent, with a volatility of 0.81 and an autocorrelation of 0.44 , relative to the set-up with no capital, with a volatility of 1.07 and an autocorrelation of 0.52 . The cross-country correlation of consumption is also lower in the benchmark with capital, 0.20 versus $0.28^{20}$. These facts, and the mechanics of volatility described in (73), explain how the model still manages to generate a very volatile real exchange rate.

Another significant insight from Table 2 is that the benchmark model (IAC) appears to perform remarkably well in terms of matching key international business cycle statistics. The volatility of consumption, net exports and real exports and imports is roughly in line with the data. The benchmark is able to reproduce some of the trademark differences between exports and imports. For instance, it produces a lower correlation between domestic output and exports than between domestic output and imports, 0.20 and 0.62 respectively. It produces more volatility for imports than exports, although it often understates the magnitude of the exports volatility and induces a negative correlation between exports and imports ${ }^{21}$. All these features are otherwise hard to replicate in a model with flexible prices and no home bias (see, e.g., Engel and Wang, $\left.2007^{22}\right)$.

\footnotetext{
${ }^{19}$ Steinsson (2008) develops two main variants of his model without capital: the homogenous labor market model, and the heterogenous market model. The difference between the two variants is in the degree of 'strategic complementarity' in the Phillips curve. In other words, the slope of the Phillips curve is flatter under heterogenous labor markets. Steinsson (2008) shows that heterogenous labor markets induce higher persistence in response to a monetary shock, although still below the data, at the expense of lower real exchange rate volatility relative to consumption. However, it does not show whether consumption volatility varies between specifications. The underlying assumption in our model is that labor markets are competitive and labor itself is an homogeneous production factor. Hence, our model is comparable to Steinsson's (2008) homogenous labor market model.

${ }^{20}$ The elasticity of intertemporal substitution might be a little bit higher than what is needed to reconcile the volatilities of consumption and the real exchange rate with the cross-correlation of consumption. Hence, even though the IAC model matches the volatility of consumption and the real exchange rate, it generates less consumption cross-correlation than the data ( 0.20 versus 0.33).

${ }^{21}$ Our sensitivity analysis also involved examing the role played by the home bias parameter. We tried an alternative model set-up where we re-calibrated the home bias parameters (simultaneously with the adjustment cost parameter, and the volatility and the correlation of shock innovations) to match the volatility of real imports and real exports in response to a monetary shock. In the IAC specification this requires us to set $\phi_{F}=0.22$, instead of using the value of 0.06 in our benchmark calibration.

${ }^{22}$ However, we also find that sticky prices and home bias in consumption and investment help account for differences in the business cycle features of exports and imports.
} 
The model also implies a correlation between net exports and GDP of -0.45 , similar to the empirical correlation of -0.47 . The autocorrelation statistics illustrate that the benchmark model (IAC) as well as the model with no capital (NoC) do not create enough persistence, and not only on consumption and real exchange rates. For example, the theoretical autocorrelation of GDP is 0.62 , which is less than the 0.87 observed in the data.

The failure of sticky-price models to generate endogenous persistence from monetary policy shocks has been pointed out in a closed economy setting by CKM (2000) and in an open economy setting by CKM (2002). The results in Table 2 suggests that neither the benchmark model nor the model without capital can resolve the persistence anomaly.

\subsubsection{Specification Robustness}

This section examines the sensitivity of our results to alternative specifications of the adjustment cost functions. The investment adjustment cost (IAC) case adopted as our benchmark makes capital adjustment more 'costly' relative to the more conventional capital adjustment cost (CAC) function used by CKM (2002). With IAC costs, households are penalized for altering the growth rate of investment (see equations (55) and (57)) unlike CAC costs where it is costly to alter the investment-to-capital ratio (see equations (18) and (20)). For completeness, we also consider the case of no capital adjustment costs (NAC).

The simulation results from the two additional experiments are summarized in Table 2, columns 4 and 5 respectively, under the headers 'CAC' and 'NAC'. The key insight from these experiments is that the real exchange rate dynamics generated by the model depend crucially on whether adjustment costs are added to the law of motion for capital or not. Without adjustment costs (NAC), the model implies a very volatile investment series, 5.08 times as volatile as output versus 3.38 times in the data. Households smooth their consumption in response to monetary shocks by adjusting their capital stock freely. Not surprisingly, the NAC case generates a very smooth consumption series, where the volatility of consumption equals 0.03 . The low volatility of consumption, in turn, translates into very little real exchange rate volatility (only 0.19 times the volatility of output).

This model setup also generates very low persistence in GDP, investment and employment but, actually, high persistence in consumption and the real exchange rate. The consumption and real exchange rate autocorrelations are in the neighborhood of 0.78 , surprisingly close to their empirical counterparts.

Another key insight is that the functional form of the adjustment cost function also does matter. The CKM-type adjustment costs (CAC) imply a ratio of consumption to GDP volatility of 0.49 . Relative to the benchmark case (IAC), the CAC model generates only half the consumption volatility. Our intuition is

that relative to the IAC case, now it is less costly to change the level of investment. Households can more easily smooth consumption by adjusting their investment margin much more on impact. Since the crosscorrelation of consumption is quite similar in the IAC and CAC models, this lower volatility of consumption mechanically translates into lower real exchange rate volatility relative to the IAC benchmark (only 3.09 times the volatility of output versus 5.13 in the IAC case).

But in terms of real exchange rate persistence, the CAC model does not differ markedly from our benchmark. They both generate insufficiently low theoretical autocorrelations in the neighborhood of $0.44-0.45$. 


\subsection{Real Shocks}

The second set of our experiments assumes that all exogenous disturbances are real shocks. The motivation for carrying out this exercise is twofold: First, the international real business cycle literature has always emphasized the importance of real shocks driving the business cycle. Second, Steinsson (2008) has shown that a model with real shocks (albeit one without capital) has the ability to match the empirical persistence and volatility of the real exchange rates. To shed light on the relationship between capital accumulation and real exchange rate dynamics, we compare simulation results from a model with capital accumulation (IAC) with results from a model with no capital (NoC).

\subsubsection{Impulse Responses}

Figure 2 shows impulse response functions for a positive domestic real shock (i.e., an increase in $\widehat{\varepsilon}_{t}^{a}$ ) in the two models (IAC) and (NoC). Higher productivity increases output on impact, lowers employment, brings real marginal costs down and, therefore, tends to lower CPI inflation. ${ }^{23}$ All of this creates conflicting objectives for monetary policy, because output and inflation move in opposite directions. The higher output in the domestic economy creates a larger worldwide supply of domestic goods. To clear the goods market, either domestic aggregate demand (i.e., consumption and investment) has to rise and/or net exports has to increase.

In the benchmark case with capital (IAC), the adjustment mainly comes about via a large rise in domestic investment and a small increase in both net exports and domestic consumption. In the model with no capital $(\mathrm{NoC})$, demand and supply equate through a large rise in both domestic consumption and net exports. This in turn requires a larger movement in relative prices for the external sector to adjust and, in particular, a larger rise in the real exchange rate (a real domestic depreciation) than what is needed in a model with capital.

The impulse responses illustrate that the real shock triggers a hump-shaped response in consumption and the real exchange rate for both the models with and without capital. This hump-shaped impulse responses arise because of the conflicting monetary policy objectives between output and inflation, as discussed in Steinsson (2008). ${ }^{24}$ In addition, Figure 2 confirms that the magnitude of the response is much greater in the model without capital. At its peak around the fourth quarter, the real exchange increases by almost $50 \%$ more in the model without capital.

\section{[Insert Figure 2 about here]}

Summing up, households have more difficulty smoothing consumption without access to physical capital (the intertemporal channel). Hence, the perfect international risk-sharing condition in (14) implies a greater real exchange rate depreciation since consumption increases by more (and becomes more volatile) in a model without capital.

\footnotetext{
${ }^{23}$ The results of the simulation for CPI inflation and nominal interest rates are discussed in the paper, but not always reported. They can be obtained directly from the authors upon request.

${ }^{24}$ The deflationary effects from the positive real shock causes the domestic monetary authorities to lower domestic nominal interest rates to balance their conflicting policy objectives, and to lead real interest rates into negative territory over time. For a while, this reinforces the tendency to consume more and save less, and induce more investment through the investment equations. This subsequent rise in consumption and investment boosts demand, hence triggering the hump-shaped response of consumption and real exchange rates.
} 
What appears to be more surprising is that domestic imports tend to stabilize quickly in the benchmark model with capital (IAC), while they take a big dip in the model without capital (NoC). Because of the import content in investment, any rise in investment requires a rise in imports. This additional demand partly offsets the decline in imports stemming from the expenditure-switching effect induced by the real exchange rate. In other words, it appears that for our calibration the 'income effect' quickly overtakes the 'relative price effect' specifically on imports. The importance of investment goods in trade has also been argued recently by Engel and Wang (2007).

\subsubsection{Theoretical Moments}

The results for the benchmark case are reported in Table 3, column 2, under the header 'IAC'. The case with no capital can be found in column 3, under the header 'NoC'. For the benchmark case (IAC), the real exchange rate is around 1.64 times as volatile as output, while in the data the real exchange rate is 5.14 times more volatile than GDP. Hence, it does not appear that a model with capital and real shocks can resolve the international pricing puzzle. However, the model with capital generates a sufficiently persistent real exchange rate since the theoretical autocorrelation of 0.84 even exceeds the 0.78 observed in the data.

In contrast, a model with no capital $(\mathrm{NoC})$ generates roughly twice the real exchange rate volatility as the benchmark model, that is 3.14 times the volatility of output. Real exchange rates are also highly persistent with an autocorrelation of 0.85 in the model without capital. Both findings are consistent with the evidence presented by Steinsson (2008). While neither model can rely on real shocks alone to generate enough real exchange rate volatility, real shocks do help account for the persistence anomaly and eliminating capital tends to amplify their effect on the volatility of the real exchange rate.

[Insert Table 3 about here]

As with monetary shocks, the investment (intertemporal) channel plays a critical role here. Without access to physical capital, households have more difficulty smoothing consumption. So consumption and the real exchange rate become more volatile in the $\mathrm{NoC}$ case, by the mechanics at play in (73). In the benchmark with capital (IAC), consumption is too smooth relative to the data ( 0.39 times as volatile as output versus 0.81 times in the data). However, consumption, investment and output exhibit a high degree of persistence that comes close to matching their empirical counterparts.

Turning now to other business cycle moments, the model with capital (IAC) generates a cross-country correlation of consumption at 0.65 that is considerably higher than in the data, where it stands at only 0.33. The cross-country correlation of GDP at 0.44 is matched by construction, but then consumption endogenously becomes more correlated than GDP unlike what we observe in the data. In the model without capital $(\mathrm{NoC})$, consumption is more than twice as volatile as in the IAC case ( 0.91 times the volatility of output versus 0.39 times). Also the consumption cross-correlation is 0.76 in the NoC, which is higher than the 0.65 reported in the IAC case. However, the increase in the volatility of consumption suffices to almost double the real exchange rate volatility that the model without capital (NoC) can get from a domestic real shock.

In summary, while real shocks can generate sufficiently persistent real exchange rates in a model with capital (IAC) and a model without capital, the lower volatility of consumption in the model with capital

(and the high consumption cross-correlation) can only be consistent with a lower real exchange rate volatility 
under perfect international risk-sharing. Hence, models with capital have more difficulty resolving the PPP puzzle relative to models without capital such as Steinsson's (2008).

\subsubsection{Specification Robustness}

This section examines how the model properties change when alternative adjustment functions are being considered in place of the IAC. The simulation results for the CKM-style adjustment costs are summarized in Table 3, column 4, under the header 'CAC'. The case of no adjustment costs appears in column 5 , under the header 'NAC'. The interpretation of the results is similar to the one given for the experiment with monetary shocks. The less costly it is to alter the capital stock, the greater the ability for households to smooth their consumption.

As a result, consumption is very smooth in the NAC case and less so in the CAC case (0.15 times and 0.35 times as volatile as output, respectively). The smooth consumption series translates into real exchange rates that are not very volatile (only 0.56 times as volatile as output in the NAC case and 1.51 times as volatile in the $\mathrm{CAC}$ setup). Interestingly, while the functional form of adjustment costs played a large role in the case of monetary shocks, the simulation results suggest that for real shocks there are no large differences between the CAC and the IAC specifications. In fact, the volatility and persistence of all variables is roughly similar in both cases.

\section{Sensitivity Analysis}

This section examines the sensitivity of our results to model variations that have been either explored or proposed elsewhere in the literature.

\subsection{Investment-Specific Shocks}

Christiano, et al. (2005) and Justiniano and Primiceri (2008) have recently pointed out that investmentspecific shocks can be a key driver for the business cycle, while Raffo (2008b) has argued that these shocks are important to help us understand terms of trade. Hence, an unavoidable question is can these shocks also resolve the PPP puzzle?

We have therefore re-simulated our benchmark model (IAC) assuming that investment-specific shocks are the only exogenous disturbances. Table 4, column 2, contains the results for the benchmark. For completeness, we have also examined the role of these shocks in combination with capital adjustment costs $(\mathrm{CAC})$ and with no adjustment costs (NAC). The simulation results from these experiments are summarized in Table 4, column 4 and 5 .

[Insert Table 4 about here]

The general message from Table 4 is that investment-specific shocks are not likely to be the most relevant force to induce data-comparable dynamics for the real exchange rate within an open-economy, sticky price model. While the IAC model does a good job at matching employment volatility (it becomes 0.64 times as volatile as output against 0.66 in the data), consumption is too smooth (only 0.39 times as volatile as output). Moreover, there is too much consumption cross-correlation across countries ( 0.65 versus 0.33 in the 
data) and as a result the real exchange rate is not volatile enough. The volatility of the real exchange rate is only 1.63 times that of output instead of 5.14 times as in the data.

However, investment-specific shocks combined with capital adjustment costs do imply a very persistent real exchange rate series. The autocorrelation of the real exchange rate is 0.96 in the benchmark case (IAC), and 0.93 in the CAC setup. Figure 3 plots the impulse response functions for a positive domestic investment-specific shock.

\section{[Insert Figure 3 about here]}

While these shocks are temporary in nature, they appear to trigger model dynamics that take a very long time to propagate its way through the system. For instance, domestic investment only appears to peak $12-14$ quarters following an investment-specific shock. In contrast, as Figures 1 and 2 show, domestic

investment peaks 4 quarters after a monetary shock and 8 quarters after a real shock. So investment-specific shocks have the potential to generate lots of persistence, but cannot resolve the international pricing puzzle.

\subsection{Capital Utilization}

Christiano, et al. (2005) have shown in a closed-economy framework how variable capital utilization can help generate persistent output effects following a monetary shock. It seems a natural question to ask whether adding capital utilization in the same spirit as Christiano, et al. (2005) can generate volatile and persistent real exchange rates in an open-economy, sticky-price model. We re-simulate the IAC model, the CAC model and the NAC model for each one of the 3 different types of shocks (real, monetary and investment-specific) to provide an answer to that. The simulation results are summarized in the final 3 columns in Tables 2, 3 and 4 .

The most interesting results are for the case of monetary shocks in Table 2, columns 6 to 8 . The benchmark case with capital utilization (under the header 'IAC+CU') only produces consumption volatility of 0.44 times that of output, and real exchange rate volatility of 2.65 times that of output. Contrast this with the benchmark case without capital utilization (IAC), where consumption and real exchange rate volatility relative to output is 0.81 times and 5.13 times respectively. At the same time, the real exchange rate persistence with capital utilization decreases to merely 0.38 versus 0.44 in the benchmark IAC case.

It appears that adding capital utilization impedes or hampers the model's ability to resolve the $P P P$ puzzle. Our intuition is that capital utilization offers a way, albeit a costly one, to get around the adjustment constraints on investment. In other words, capital utilization allows households to make better use of the intertemporal smoothing channel. Hence, resulting in lower consumption and real exchange rate volatilities. Adding capital utilization to a model featuring the alternative capital adjustment function (CAC) yields a similar conclusion.

\subsection{Real and Monetary Shocks}

Up to this point, our simulations have assumed that international business cycles are either driven by monetary shocks, by real shocks or by investment-specific shocks alone. Here, instead, we explore the case where our open economy model is subject to both exogenous monetary and real disturbances. The results for the benchmark case (IAC) are summarized in Table 5, column 2. Column 3 contains results for the model without capital (NoC). 


\section{[Insert Table 5 about here]}

The main observation from Table 5 is that the benchmark IAC model, when simulated with both real and monetary shocks, produces real exchange rates that are 3.12 times more volatile than GDP. While this value is less than what we observe in the data, where we find that the real exchange rate is 5.14 times as volatile as GDP, the benchmark now produces twice as much real exchange rate volatility as was the case with just real shocks. The model without capital (NoC) is, once again, capable of almost perfectly replicating the empirically observed real exchange rate volatility, 5.23 times versus 5.14 times the volatility of GDP in the data. So our main message remains robust, namely that models without capital suffer from a 'volatility bias' that tends to understate the true magnitude of the international pricing puzzle.

Interestingly, the benchmark IAC model with both types of shocks implies a real exchange rate persistence that is only slightly higher than the autocorrelation we compute with just monetary shocks. Here, the autocorrelation of the real exchange rate is 0.50 , while it is 0.44 in the case of monetary shocks only. Why is this finding important? Our earlier analysis has somewhat validated the results of Steinsson (2008) that real shocks have the potential to resolve the persistence anomaly of real exchange rates, albeit in a model without capital. However, Table 5 illustrates that when monetary shocks are added as one (although not the exclusive) source of business cycle fluctuations, the theoretical autocorrelation of the real exchange rate drops significatively to 0.50 .

Therefore it appears that in this class of open-economy, sticky-price models, even if real shocks are the dominant source on business cycle fluctuations for most macro aggregates, the real exchange rate dynamics are still disproportionately impacted by the monetary shocks.

[Insert Table 6 about here]

This is confirmed by Table 6 which contains a variance decomposition for the benchmark model. Each column indicates the fraction of variance coming from the 4 shocks (domestic and foreign monetary policy and productivity shocks) in the benchmark IAC model. We note that almost $80 \%$ of all the variability in the real exchange rate can be attributed to monetary policy shocks. So even though our model calibration assumes that real shocks are 4 times as volatile as monetary shocks, real exchange rate dynamics including the volatility and persistence are still tied down mostly by the effects and propagation of the monetary shocks. $^{25}$

\section{Concluding Remarks}

In this paper, we use an open-economy, sticky-price model with pricing-to-market and complete asset markets to examine the link between real exchange rate dynamics and what the model assumes about physical capital. We show that this class of models without capital accumulation tend to suffer from a 'volatility bias'; that is, they often understate the true magnitude of the international pricing puzzle. In a world without capital, households cannot smooth consumption easily and rely more heavily on (intratemporal) international trading in the goods markets for risk-sharing purposes. As a result, consumption and, hence, real exchange rates are

\footnotetext{
${ }^{25}$ We would speculate that the disproportionate importance of monetary shocks may be due to the fact that the degree of 'complementarity on consumption' (in the Phillips curve) is pretty high in our specification, which makes the inflation dynamics particularly susceptible to monetary shocks.
} 
more volatile relative to models that feature capital accumulation. Our results suggest that resolving the international pricing puzzle remains challenging once capital is included.

By their very own nature, adjustment costs make it more costly to smooth consumption through the intertemporal margin. Hence, consumption becomes more volatile and so does the real exchange rate. In fact, we show that such a model combined with monetary policy shocks has the potential to replicate the observed real exchange rate volatility. But, when we assume more realistically that business cycles are partly (if not predominantly) driven by real shocks, the same model produces real exchange rates that are far less volatile than in the data.

Addressing the CKM (2002) persistence anomaly is not easy either. This paper shows that the anomaly in response to monetary shocks is robust to adding capital or not, to the specification of the adjustment costs in the law of motion for capital, and even to the addition of capital utilization. Persistence is easier to get from real or investment-specific shocks, but then it is rather difficult to match the volatility of the real exchange rate for a sensible calibration. In our view, the PPP puzzle is still very much alive and well. 


\section{References}

[1] Backus, David K. and Gregor W. Smith (1993): "Consumption and Real Exchange Rates in Dynamic Economies with Non-Traded Goods". Journal of International Economics, vol. 35 (3-4), pp. 297-316.

[2] Backus, David K., Patrick J. Kehoe and Finn E. Kydland (1995): "International Business Cycles: Theory and Evidence", in Thomas F. Cooley (ed.) Frontiers of Business Cycle Research, pp. 331-356. Princeton University Press: Princeton, New Jersey, USA.

[3] Basu, Susanto (1996): "Procyclical Productivity: Increasing Returns or Cyclical Utilization?". Quarterly Journal of Economics, vol. 111 (3), pp. 719-751.

[4] Benigno, Gianluca (2004): "Real Exchange Rate Persistence and Monetary Policy Rules". Journal of Monetary Economics, vol. 51 (3), pp. 473-502.

[5] Bergin, Paul R. and Robert C. Feenstra (2001): "Pricing-to-Market, Staggered Contracts, and Real Exchange Rate Persistence". Journal of International Economics, vol. 54 (2), pp. 333-359.

[6] Blanchard, Olivier J. and Charles M. Kahn (1980): "The Solution of Linear Difference Models Under Rational Expectations". Econometrica, vol. 48 (5), pp. 1305-1311.

[7] Blundell, Richard and Thomas MaCurdy (1999): "Labor Supply: A Review of Alternative Approaches", in O. Ashenfelter and D. Card (eds.) Handbook of Labor Economics, vol. 3, pp. 1559-1665. Elsevier Science B.V., North Holland, Amsterdam.

[8] Browning, Martin, Lars Peter Hansen and James J. Heckman (1999): "Micro Data and General Equilibrium Models", in J. B. Taylor and M. Woodford (eds.) Handbook of Macroeconomics, vol. 1, pp. 543-633. Elsevier Science B.V., North Holland, Amsterdam.

[9] Calvo, Guillermo A. (1983): "Staggered Prices in a Utility-Maximizing Framework". Journal of Monetary Economics, vol. 12 (3), pp. 383-398.

[10] Canzoneri, Matthew B., Robert E. Cumby and Behzad T. Diba (2007): "The Cost of Nominal Rigidity in NNS Models". Journal of Money, Credit and Banking, vol. 39 (7), pp. 1563-1586.

[11] Carvalho, Carlos and Fernanda Nechio (2008): "Aggregation and the PPP Puzzle in a Sticky Price Model". Mimeo, Economics Department, Princeton University.

[12] Chari, V. V., Patrick J. Kehoe and Ellen R. McGrattan (2000): "Sticky Price Models of the Business Cycle: Can the Contract Multiplier Solve the Persistence Problem?". Econometrica, vol. 68 (5), pp. 1151-1179.

[13] Chari, V. V., Patrick J. Kehoe and Ellen R. McGrattan (2002): "Can Sticky Price Models Generate Volatile and Persistent Real Exchange Rates?". Review of Economic Studies, vol. 69 (240), pp. 533-563.

[14] Christiano, Lawrence J., Martin Eichenbaum and Charles L. Evans (2005): "Nominal Rigidities and the Dynamic Effects of a Shock to Monetary Policy". Journal of Political Economy, vol. 113 (1), pp. $1-45$.

[15] Clarida, Richard, Jordi Galí and Mark Gertler (1998): "Monetary Policy Rules in Practice: Some International Evidence". European Economic Review, vol. 42 (6), pp. 1033-1067.

[16] Clarida, Richard, Jordi Galí and Mark Gertler (2000): "Monetary Policy Rules and Macroeconomic Stability: Evidence and Some Theory". Quarterly Journal of Economics, vol. 115 (1), pp. 147-180.

[17] Cooley, Thomas F. and Edward C. Prescott (1995): "Economic Growth and Business Cycles", in Thomas F. Cooley (ed.) Frontiers of Business Cycle Research, chapter 1, pp. 1-38. Princeton University Press: Princeton, New Jersey, USA. 
[18] Dornbusch, Rudiger (1976a): "Expectations and Exchange Rate Dynamics". Journal of Political Economy, vol. 84 (6), pp. 1161-1176.

[19] Dornbusch, Rudiger (1976b): "Exchange Rate Expectations and Monetary Policy". Journal of International Economics, vol. 6 (3), pp. 231-244.

[20] Engel, Charles and Jian Wang (2007): "International Trade in Durable Goods: Understanding Volatility, Cyclicality, and Elasticities". GMPI Working Paper, No. 3, Federal Reserve Bank of Dallas.

[21] Galí, Jordi and Tommaso Monacelli (2005): "Monetary Policy and Exchange Rate Volatility in a Small Open Economy". Review of Economic Studies, vol. 72 (3), pp. 707-734.

[22] Greenwood, Jeremy, Zvi Hercowitz, and Gregory W. Huffman (1988): "Investment, Capacity Utilization, and the Real Business Cycle". American Economic Review, vol. 78 (3), pp. 402-417.

[23] Groen, Jan J. J. and Akito Matsumoto (2004): "Real Exchange Rate Persistence and Systematic Monetary Policy Behavior". Bank of England Working Paper, No. 231, Bank of England.

[24] Groth, Charlotta and Hashmat Khan (2007): "Investment Adjustment Costs: An Empirical Assessment". Carleton Economic Papers, No. 07-08, Carleton University.

[25] Heathcote, Jonathan and Fabrizio Perri (2002): "Financial Autarky and International Business Cycles". Journal of Monetary Economics, vol. 49 (3), pp. 601-627.

[26] Heathcote, Jonathan and Fabrizio Perri (2004): "Financial Globalization and Real Regionalization". Journal of Economic Theory, vol. 119 (1), pp. 207-243.

[27] Juillard, Michel (2003): "Dynare: A Program for Solving Rational Expectations Models". CEPREMAP, available at www.cepremap.cnrs.fr/dynare/

[28] Justiniano, Alejandro, Giorgio E. Primiceri, and Andrea Tambalotti (2008): "Investment Shocks and Business Cycles". FRB of New York Staff Report, No. 322, Federal Reserve Bank of New York.

[29] Justiniano, Alejandro and Giorgio E. Primiceri (2008): "The Time-Varying Volatility of Macroeconomic Fluctuations". American Economic Review, vol. 98 (3), pp. 604-641.

[30] Lai, Huiwen and Daniel Trefler (2002): "The Gains from Trade with Monopolistic Competition: Specification, Estimation and Mis-Specification". NBER Working Paper, No. 9169, National Bureau of Economic Research, Inc.

[31] Martínez-García, Enrique (2007): "A Monetary Model of the Exchange Rate with Informational Frictions". GMPI Working Paper, No. 2, Federal Reserve Bank of Dallas.

[32] Martínez-García, Enrique and Jens Søndergaard (2008): "Technical Note on 'The Real Exchange Rate in Sticky Price Models: Does Investment Matter?'". GMPI Working Paper, No. 16, Federal Reserve Bank of Dallas.

[33] Rabanal, Pau, Juan F. Rubio-Ramírez and Vicente Tuesta (2008): "Cointegrated TFP Processes and International Business Cycles". Mimeo, Economics Department, Duke University.

[34] Raffo, Andrea (2008a): "Net Exports, Consumption Volatility and International Business Cycle Models". Journal of International Economics, vol. 75 (1), pp. 14-29.

[35] Raffo, Andrea (2008b): "Technology Shocks: Novel Implications for International Business Cycles". Mimeo, Board of Governors of the Federal Reserve System.

[36] Steinsson, Jón (2008): "The Dynamic Behavior of the Real Exchange Rate in Sticky Price Models". American Economic Review, vol. 98 (1), pp. 519-533. 
[37] Søndergaard, Jens (2004): "Variable Capital Utilization, Staggered Wages and Real Exchange Rate Persistence". Essays on Real Exchange Rate Dynamics, Georgetown University, Washington, DC.

[38] Taylor, John B. (1993): "Discretion Versus Policy Rules in Practice". Carnegie-Rochester Conference Series, vol. 39, pp. 195-214.

[39] Warnock, Francis E. (2003): "Exchange Rate Dynamics and the Welfare Effects of Monetary Policy in a Two-Country Model with Home-Product Bias". Journal of International Money and Finance, vol. 22 (3), pp. 343-363. 


\section{Appendix}

\section{A Description of the Dataset}

We take the United States to be the home country, and identify the foreign country with the 12 member country Euro-zone ${ }^{26}$. We collect all quarterly data spanning the post-Bretton Woods period from 1973q1 through 2006q4 (for a total of 136 observations per series). All data (except interest rates and nominal exchange rates) is seasonally adjusted. Whenever available, we rely on aggregate data obtained from Thomson Datastream. However, the U.S. civilian non-institutional population is from Haver Analytics, the Euro-zone CPI is from Bloomberg, the Euro-zone employment combines data from the ECB and the Area-Wide Model (AWM), and the Euro-zone workforce is from SourceOECD.

Data Series. We collect data on real output (rgdp), real private consumption (rcons), real private fixed investment (rinv), consumer price indexes (cpi), nominal interest rates (int), real exports (rx), real imports (rm), employment (emp), population size (n), and nominal exchange rates (ner) for the U.S. We also have data on real output (rgdp), real private consumption (rcons), real private fixed investment (rinv), consumer price indexes (cpi), employment (emp), and population size (n) for the Euro-zone.

- Real output (rgdp), real private consumption (rcons) and real private fixed investment (rinv). Data at quarterly frequency, transformed to millions of national currency (either U.S. Dollars or Euros), at constant prices, and seasonally adjusted. Source: Bureau of Economic Analysis, and OECD's Quarterly National Accounts.

- Consumer price indexes (cpi). Data at quarterly frequency, indexed $(2000=100)$, and seasonally adjusted. Source: OECD's Economic Outlook, and OECD's Main Economic Indicators. (We seasonallyadjust the Euro-zone CPI with the multiplicative method X12).

- U.S. Treasury bill in the secondary market at 3-month maturity (int): Data at quarterly frequency, expressed in percentages, and not seasonally adjusted. Source: U.S. Federal Reserve.

- Real exports (rx) and real imports (rm). Data at quarterly frequency, transformed to millions of U.S. Dollars, and seasonally adjusted. Source: Bureau of Economic Analysis.

- Employment (emp). Data at quarterly frequency, expressed in thousands, and seasonally adjusted. Source: OECD's Economic Outlook, and European Central Bank (ECB). (For Euro-zone employment, we splice together the ECB's official series after 1991, with the ECB's Area-Wide Model series prior to 1991).

- Working-age Population between 15/16 and 64 years of age (pop): Data at quarterly frequency, expressed in thousands, and seasonally adjusted. Sources: Bureau of Labor Statistics, and OECD's Economic Outlook. (For U.S. working-age population, we take the difference between civilian non-institutional population 16 and over and civilian non-institutional population 65 and over. We also seasonally-adjust the resulting series with the multiplicative method X12. For the Euro-zone working-age population, we splice together the OECD's working-age series including 15 to 64 year olds with data on West Germany only prior to 1991. Then, we seasonally-adjust the series with the multiplicative method X12).

\footnotetext{
${ }^{26}$ Austria, Belgium, Finland, France, Germany, Greece, Ireland, Italy, Luxembourg, Netherlands, Portugal, and Spain. The sample period considered ends up before Slovenia became a member of the Euro-zone in January 2007.
} 
- Nominal exchange rate (ner). Data at quarterly frequency, quoted as U.S. Dollars per Euro, and not seasonally adjusted. Source: WM/Reuters.

Updating Procedure. The real output (rgdp), real private consumption (rcons), real private fixed investment (rinv), real exports (rx), real imports (rm), and employment (emp) are expressed in per capita terms dividing each one of these series by the population size (pop). We compute the real exchange rate, $R S_{t} \equiv \frac{S_{t} P_{t}^{*}}{P_{t}}$, based on the data for the nominal exchange rate, the U.S. CPI and the Euro-zone $\mathrm{CPI}^{27}$. We compute the real net export share over GDP, $\frac{E X_{t}-I M_{t}}{Y_{t}} \times 100$, based on the data for the U.S. real imports, the U.S. real exports and the U.S. real GDP. We express all variables in logs and multiply them by 100, except the nominal short-term interest rate (int), and the real net export share (both of them expressed in percentages). At this point, we also define the CPI inflation as the first difference of the CPI level. Finally, all series are Hodrick-Prescott (H-P) filtered to eliminate their underlying trend. We use the H-P smoothing parameter at 1600 for our quarterly dataset.

\section{B On the Statistical Properties of the RER}

The perfect international risk-sharing condition in equation (14), i.e.

$$
\widehat{c}_{t}-\widehat{c}_{t}^{*} \approx \sigma \widehat{r s}_{t}
$$

imposes a strong linkage between the real exchange rate and consumption. Based on this equilibrium condition, we can write the variance of the real exchange rate relative to the variance of output as follows,

$$
\frac{\operatorname{var}(\widehat{r s})}{\operatorname{var}(\widehat{y})} \cong \frac{1}{\sigma^{2}}\left[\frac{\operatorname{var}(\widehat{c})}{\operatorname{var}(\widehat{y})}+\frac{\operatorname{var}\left(\widehat{c}^{*}\right)}{\operatorname{var}(\widehat{y})}-2 \operatorname{corr}\left(\widehat{c}, \widehat{c}^{*}\right) \frac{\operatorname{std}(\widehat{c})}{\operatorname{std}(\widehat{y})} \frac{\operatorname{std}\left(\widehat{c}^{*}\right)}{\operatorname{std}(\widehat{y})}\right]
$$

Similarly, the first-order autocorrelation of the real exchange rate can be written as,

$$
\begin{aligned}
\operatorname{corr}(\widehat{r s}, \widehat{r s}-1) \equiv & \frac{\operatorname{cov}(\widehat{r s}, \widehat{r s}-1)}{\operatorname{var}(\widehat{r s})} \cong \frac{\frac{1}{\sigma^{2}} \operatorname{cov}\left[\widehat{c}-\widehat{c}^{*}, \widehat{c}_{-1}-\widehat{c}_{-1}^{*}\right]}{\operatorname{var}(\widehat{r s})} \\
= & \operatorname{corr}\left(\widehat{c}, \widehat{c}_{-1}\right)\left(\frac{\frac{1}{\sigma^{2}} \operatorname{var}(\widehat{c})}{\operatorname{var}(\widehat{r s})}\right)+\operatorname{corr}\left(\widehat{c}^{*}, \widehat{c}_{-1}^{*}\right)\left(\frac{\frac{1}{\sigma^{2}} \operatorname{var}\left(\widehat{c}^{*}\right)}{\operatorname{var}(\widehat{r s})}\right)- \\
& -\frac{\frac{1}{\sigma^{2}}\left[\operatorname{cov}\left(\widehat{c}, \widehat{c}_{-1}^{*}\right)+\operatorname{cov}\left(\widehat{c}^{*}, \widehat{c}_{-1}\right)\right]}{\operatorname{var}(\widehat{r s})}
\end{aligned}
$$

where $\operatorname{corr}\left(\widehat{c}, \widehat{c}_{-1}\right) \equiv \frac{\operatorname{cov}\left(\widehat{c}, \widehat{c}_{-1}\right)}{\operatorname{var}(\widehat{c})}$ and $\operatorname{corr}\left(\widehat{c}^{*}, \widehat{c}_{-1}^{*}\right) \equiv \frac{\operatorname{cov}\left(\widehat{c}^{*}, \widehat{c}_{-1}^{*}\right)}{\operatorname{var}\left(\widehat{c}^{*}\right)}$. The PPP puzzle is often framed in terms of both the persistence and volatility of the real exchange rate. Hence, the relationships established in equations

\footnotetext{
${ }^{27}$ Other researchers, instead, prefer the volatility of the effective U.S. Dollar exchange rate for comparability with other trade variables for which we do not have bilateral data. Obviously, this produces a significatively lower real exchange rate persistence, since many U.S. trading partners maintained fixed currencies to the dollar for most of the sample period (e.g., China and implicitly Japan). This means that the international pricing puzzle does not look so bad with those numbers. We believe, however, that our numbers are consistent with those reported in the literature (e.g., CKM, 2002, Steinsson, 2008), appropriate for our question (since we focus on the PPP puzzle rather than on other trade anomalies), and internally consistent with our model. Because we are exploring the bilateral linkages between the U.S. and the Euro-zone; and, because our real exchange rate is build exclusively on a group of countries for which the exchange rates were flexible for the entire sample period, which is the underlying assumption of our model.
} 
(B.1) and (B.2) are important to determine the weaknesses and strengths of our theory, and of any theory build around the same approximation to perfect international risk-sharing as ours.

The inherent symmetry of the two-country model allows us a way to express these linkages more compactly. Symmetry is a very convenient outcome because it implies that the theoretical variances of domestic and foreign consumption are equalized, i.e. $\operatorname{var}(\widehat{c})=\operatorname{var}\left(\widehat{c}^{*}\right)$, and also that the first-order autocorrelations are the same, i.e. $\operatorname{corr}\left(\widehat{c}, \widehat{c}_{-1}\right)=\operatorname{corr}\left(\widehat{c}^{*}, \widehat{c}_{-1}^{*}\right)$. In fact, the symmetric property can be shown to hold in equilibrium for all other pairs of domestic and foreign endogenous variables. However, consumption (and all other variables) is not perfectly correlated across countries, i.e. $\operatorname{corr}\left(\widehat{c}, \widehat{c}^{*}\right) \neq 1$.

Volatility of the RER. Symmetry alone suffices to help us reduce equation (B.1) to,

$$
\frac{\operatorname{var}(\widehat{r s})}{\operatorname{var}(\widehat{y})} \cong \frac{2}{\sigma^{2}}\left[1-\operatorname{corr}\left(\widehat{c}, \widehat{c}^{*}\right)\right] \frac{\operatorname{var}(\widehat{c})}{\operatorname{var}(\widehat{y})}
$$

which clearly emphasizes the importance of the consumption variance and the cross-country consumption correlation to match the variance of the real exchange rate. Furthermore, if we express the volatility of the real exchange rate relative to the volatility of consumption (instead of output), i.e.

$$
\frac{\operatorname{std}(\widehat{r s})}{\operatorname{std}(\widehat{c})} \cong \frac{1}{\sigma} \sqrt[2]{2\left(1-\operatorname{corr}\left(\widehat{c}, \widehat{c}^{*}\right)\right)}
$$

we could say that there is a one-to-one mapping between the consumption cross-correlation and the volatility of the real exchange rate embedded in equation (14), which is regulated by the elasticity of intertemporal substitution (i.e., $\sigma$ ). Accordingly, the more correlated consumption becomes across countries, the smaller should be the volatility of the real exchange rate relative to consumption.

Persistence of the RER. Manipulating equation (B.2), we can write the link between the autocorrelation of the real exchange rate and the autocorrelation of consumption in the following terms,

$$
\begin{aligned}
& \operatorname{corr}(\widehat{r s}, \widehat{r s}-1) \cong \operatorname{corr}\left(\widehat{c}, \widehat{c}_{-1}\right)\left(\frac{\frac{1}{\sigma^{2}} \operatorname{var}(\widehat{c})}{\operatorname{var}(\widehat{r} s)}\right)+\operatorname{corr}\left(\widehat{c}^{*}, \widehat{c}_{-1}^{*}\right)\left(\frac{\frac{1}{\sigma^{2}} \operatorname{var}\left(\widehat{c}^{*}\right)}{\operatorname{var}(\widehat{r} s)}\right)+ \\
& \quad+\left(\frac{\operatorname{cov}\left(\widehat{c}^{*}, \widehat{c}_{-1}^{*}\right)+\operatorname{cov}\left(\widehat{c}, \widehat{c}_{-1}\right)}{\operatorname{std}(\widehat{c}) \operatorname{std}\left(\widehat{c}^{*}\right)}\right)\left(\frac{\operatorname{cov}\left(\widehat{c}, \widehat{c}_{-1}^{*}\right)+\operatorname{cov}\left(\widehat{c}^{*}, \widehat{c}_{-1}\right)}{\operatorname{corr}\left(\widehat{c}, \widehat{c}^{*}\right)\left[\operatorname{cov}\left(\widehat{c}^{*}, \widehat{c}_{-1}^{*}\right)+\operatorname{cov}\left(\widehat{c}, \widehat{c}_{-1}\right)\right]}\right)\left(\frac{-\frac{1}{\sigma^{2}} \operatorname{corr}\left(\widehat{c}, \widehat{c}^{*}\right) \operatorname{std}(\widehat{c}) \operatorname{std}\left(\widehat{c}^{*}\right)}{\operatorname{var}(\widehat{r} s)}\right) .
\end{aligned}
$$

Then, recalling one more time the symmetric property of domestic and foreign consumption, we obtain that,

$$
\begin{aligned}
\operatorname{corr}(\widehat{r s}, \widehat{r s}-1) & \cong \operatorname{corr}\left(\widehat{c}, \widehat{c}_{-1}\right)\left\{\frac{\frac{2}{\sigma^{2}}\left[1-\left(\frac{\operatorname{cov}\left(\widehat{c}, \widehat{c}_{-1}^{*}\right)+\operatorname{cov}\left(\widehat{c}^{*}, \widehat{c}_{-1}\right)}{\operatorname{corr}\left(\widehat{c}, \widehat{c}^{*}\right)\left[\operatorname{cov}\left(\widehat{c}^{*}, \widehat{c}_{-1}^{*}\right)+\operatorname{cov}\left(\widehat{c}, \widehat{c}_{-1}\right)\right]}\right) \operatorname{corr}\left(\widehat{c}, \widehat{c}^{*}\right)\right] \operatorname{var}(\widehat{c})}{\operatorname{var}(\widehat{r} \widehat{s})}\right\} \\
& \cong \operatorname{corr}\left(\widehat{c}, \widehat{c}_{-1}\right)\left\{\frac{1-\left(\frac{\operatorname{cov}\left(\widehat{c}, \widehat{c}_{-1}^{*}\right)}{\operatorname{corr}\left(\widehat{c}, \widehat{c}^{*}\right) \operatorname{cov}\left(\widehat{c}, \widehat{c}_{-1}\right)}\right) \operatorname{corr}\left(\widehat{c}, \widehat{c}^{*}\right)}{1-\operatorname{corr}\left(\widehat{c}, \widehat{c}^{*}\right)}\right\}
\end{aligned}
$$

where the second approximation follows directly from (B.3) and the fact that the autocovariance function on the equilibrium solution is also symmetric (implying that $\operatorname{cov}\left(\widehat{c}, \widehat{c}_{-1}^{*}\right)=\operatorname{cov}\left(\widehat{c}^{*}, \widehat{c}_{-1}\right)$ ). Equation (B.4) 
shows that the first-order autocorrelation of the real exchange rate is approximately equal to the first-order autocorrelation on consumption as long as,

$$
\operatorname{corr}\left(\widehat{c}, \widehat{c}^{*}\right) \operatorname{cov}\left(\widehat{c}, \widehat{c}_{-1}\right) \approx \operatorname{cov}\left(\widehat{c}, \widehat{c}_{-1}^{*}\right)
$$

An approximation which seems to hold pretty well in all our simulations. In fact, we argue that such a result is likely to hold in general precisely because of the perfect international risk-sharing condition in equation (14).

Using equation (14) to relate domestic and foreign consumption, we can re-write the covariances $\operatorname{cov}\left(\widehat{c}, \widehat{c}_{-1}^{*}\right)$ and $\operatorname{cov}\left(\widehat{c}, \widehat{c}^{*}\right)$ as,

$$
\begin{aligned}
\operatorname{cov}\left(\widehat{c}, \widehat{c}_{-1}^{*}\right) & =\operatorname{cov}\left(\widehat{c}, \widehat{c}_{-1}\right)-\sigma \operatorname{cov}\left(\widehat{c}, \widehat{r s}{ }_{-1}\right) \\
\operatorname{cov}\left(\widehat{c}, \widehat{c}^{*}\right) & =\operatorname{var}(\widehat{c})-\sigma \operatorname{cov}(\widehat{c}, \widehat{r s})
\end{aligned}
$$

We can always project $\widehat{c}$ against $\widehat{c}_{-1}$ by least squares, which is consistent with our linear equilibrium, and derive that the best linear fit of $\widehat{c}$ in population moments is given by $\operatorname{corr}\left(\widehat{c}, \widehat{c}_{-1}\right) \widehat{c}_{-1}$. If we use this projection, we immediately obtain that,

$$
\begin{aligned}
\operatorname{cov}\left(\widehat{c}, \widehat{r s}_{-1}\right) & \approx \operatorname{cov}\left(\operatorname{corr}\left(\widehat{c}, \widehat{c}_{-1}\right) \widehat{c}_{-1}, \widehat{r s}-1\right) \\
& =\operatorname{cov}\left(\widehat{c}, \widehat{c}_{-1}\right) \frac{\operatorname{cov}(\widehat{c}, \widehat{r s})}{\operatorname{var}(\widehat{c})}
\end{aligned}
$$

where the second equality holds because of the property that the equilibrium solution is covariance-stationary (implying that $\left.\operatorname{cov}\left(\widehat{c}_{-1}, \widehat{r s}_{-1}\right)=\operatorname{cov}(\widehat{c}, \widehat{r s})\right)$. Combining the formulas derived for $\operatorname{cov}\left(\widehat{c}, \widehat{c}^{*}\right)$ and $\operatorname{cov}(\widehat{c}, \widehat{r s}-1)$ we argue that,

$$
\begin{aligned}
\operatorname{cov}\left(\widehat{c}, \widehat{r s} s_{-1}\right) & \approx \frac{\sigma^{-1}\left(\operatorname{var}(\widehat{c})-\operatorname{cov}\left(\widehat{c}, \widehat{c}^{*}\right)\right)}{\operatorname{var}(\widehat{c})} \operatorname{cov}\left(\widehat{c}, \widehat{c}_{-1}\right) \\
& =\sigma^{-1}\left(1-\operatorname{corr}\left(\widehat{c}, \widehat{c}^{*}\right)\right) \operatorname{cov}\left(\widehat{c}, \widehat{c}_{-1}\right)
\end{aligned}
$$

must be true as an approximation. Hence, putting all the pieces together, we infer that $\operatorname{cov}\left(\widehat{c}, \widehat{c}_{-1}^{*}\right)$ can be expressed as,

$$
\begin{aligned}
\operatorname{cov}\left(\widehat{c}, \widehat{c}_{-1}^{*}\right) & \approx \operatorname{cov}\left(\widehat{c}, \widehat{c}_{-1}\right)-\sigma\left[\sigma^{-1}\left(1-\operatorname{corr}\left(\widehat{c}, \widehat{c}^{*}\right)\right) \operatorname{cov}\left(\widehat{c}, \widehat{c}_{-1}\right)\right] \\
& =\operatorname{corr}\left(\widehat{c}, \widehat{c}^{*}\right) \operatorname{cov}\left(\widehat{c}, \widehat{c}_{-1}\right)
\end{aligned}
$$

which gives us exactly the condition described above to link the first-order autocorrelations of consumption and the real exchange rate. In this sense, it can be said that (B.4) reduces in practice to,

$$
\operatorname{corr}\left(\widehat{r s}, \widehat{r s}_{-1}\right) \cong \operatorname{corr}\left(\widehat{c}, \widehat{c}_{-1}\right)
$$

which tells us that the persistence of the real exchange rate and consumption are the two sides of the same coin in symmetric models, like ours, build around equation (14). We exploit this insight to shed new light on the findings in our simulation exercise. 


\section{Tables and Figures}

Table 1: Parameters used for the Benchmark Calibration.

\begin{tabular}{|c|c|c|c|c|}
\hline & & Benchmark & CKM (2002) & Steinsson (2008) \\
\hline \multicolumn{5}{|l|}{ Structural Parameters: } \\
\hline Discount Factor & $\beta$ & 0.99 & 0.99 & 0.99 \\
\hline Elasticity of Intratemporal Substitution & $\eta$ & 1.5 & 1.5 & 10 \\
\hline Elasticity of Substitution across Varieties & $\theta$ & 10 & 10 & 10 \\
\hline Elasticity of Intertemporal Substitution & $\sigma$ & $1 / 5$ & $1 / 5$ & $1 / 5$ \\
\hline (Inverse) Elasticity of Labor Supply & $\varphi$ & 3 & 5 & 3 \\
\hline Domestic Home Bias Parameter & $\dot{\phi}_{H}$ & 0.94 & 0.94 & 0.94 \\
\hline Foreign Home Bias Parameter & $\phi_{F}$ & 0.06 & 0.06 & 0.06 \\
\hline Calvo Price Stickiness Parameter & $\alpha$ & 0.75 & $N=4$ & 0.75 \\
\hline Depreciation Rate & $\delta$ & 0.021 & 0.021 & - \\
\hline Capital/Investment Adjustment Cost & $\chi, \kappa$ & varies & varies & - \\
\hline Elasticity of Capital Utilization Cost & $\lambda$ & 5.80 & - & - \\
\hline Labor Share & $\psi$ & $2 / 3$ & $2 / 3$ & - \\
\hline \multicolumn{5}{|l|}{ Parameters on the Taylor Rule: } \\
\hline Interest Rate Inertia & $\rho_{i}$ & 0.85 & 0.79 & 0.85 \\
\hline Weight on Inflation Target & $\psi_{\pi}$ & 2 & 2.15 & 2 \\
\hline Weight on Output/Consumption Target & $\psi_{y}, \psi_{c}$ & 0.5 & $0.93 / 4$ & 0.5 \\
\hline \multicolumn{5}{|l|}{ Exogenous Shock Parameters: } \\
\hline Real Shock Persistence & $\rho_{a}$ & 0.9 & 0.95 & 0.9 \\
\hline Monetary Shock Persistence & $\rho_{m}$ & 0.9 & 0 & 0.9 \\
\hline Investment Shock Persistence & $\rho_{v}$ & 0.9 & - & - \\
\hline Real Shock Correlation & $\operatorname{corr}\left(\widehat{\varepsilon}_{t}^{a}, \widehat{\varepsilon}_{t}^{a *}\right)$ & varies & 0.25 & 0 \\
\hline Monetary Shock Correlation & $\operatorname{corr}\left(\widehat{\varepsilon}_{t}^{m}, \widehat{\varepsilon}_{t}^{m *}\right)$ & varies & varies & 0.5 \\
\hline Investment Shock Correlation & $\operatorname{corr}\left(\widehat{\varepsilon}_{t}^{v}, \widehat{\varepsilon}_{t}^{v *}\right)$ & varies & - & - \\
\hline Real Shock Volatility & $\sigma\left(\widehat{\varepsilon}_{t}^{a}\right), \sigma\left(\widehat{\varepsilon}_{t}^{a *}\right)$ & varies & 0.007 & 0.01 \\
\hline Monetary Shock Volatility & $\sigma\left(\widehat{\varepsilon}_{t}^{m}\right), \sigma\left(\widehat{\varepsilon}_{t}^{m *}\right)$ & varies & varies & 0.01 \\
\hline Investment Shock Volatility & $\sigma\left(\widehat{\varepsilon}_{t}^{v}\right), \sigma\left(\widehat{\varepsilon}_{t}^{v *}\right)$ & varies & - & - \\
\hline \multicolumn{5}{|l|}{ Composite Parameters: } \\
\hline Steady State Investment Share & $\gamma_{x} \equiv \frac{(1-\psi) \delta}{\left(\frac{\theta}{\theta-1}\right)\left(\beta^{-1}-(1-\delta)\right)}$ & 0.203 & $(0.203)$ & $(-)$ \\
\hline \multirow[t]{2}{*}{ Slope of the Phillips Curve } & $\frac{(1-\alpha)(1-\alpha \beta)}{\alpha}$ & 0.086 & $(0.086)$ & $(\kappa=0.086)$ \\
\hline & $\omega \equiv \frac{\varphi \psi^{2}+(1-\psi)(1+\varphi)^{2}}{\varphi \psi+(1-\psi) \psi \varphi^{2}}$ & 1.667 & $(1.600)$ & $(1)$ \\
\hline Strategic Complementarity on Cons. & $\sigma^{-1}+\left(1-\gamma_{x}\right) \varphi \omega$ & 8.987 & $(11.379)$ & $(\zeta=8)$ \\
\hline Strategic Complementarity on Inv. & $\gamma_{x} \varphi \omega$ & 1.013 & $(1.621)$ & $(-)$ \\
\hline
\end{tabular}

This table summarizes our benchmark parameterization. Additional results on the sensitivity of certain parameters can be obtained directly from the authors upon request. The proper comparison is with CKM's (2002) variant with a Taylor rule and Steinsson's (2008) specification with homogeneous labor markets, even though Steinsson (2008) does not include capital. The composite parameters are inferred based on the parametric choices described for our benchmark, and for the models of CKM (2002) and Steinsson (2008).

For the most part, we follow the calibration strategy of CKM (2002). In CKM (2002), prices are fixed for 4 periods. In Steinsson (2008) and in our model, a Calvo parameter of 0.75 implies an average contract duration of 4 periods. CKM's (2002) Taylor rule targets expected inflation and current output, Steinsson's (2008) targets current inflation and current consumption, while in our model it targets current inflation and current output. For more details on the parametric choice, specially for the adjustment cost parameter and the volatility and correlation of innovations, read the calibration section. 
Table 2: Simulation Results (Monetary Shocks).

\begin{tabular}{|c|c|c|c|c|c|c|c|c|}
\hline & & \multicolumn{2}{|c|}{ Benchmark } & \multicolumn{2}{|c|}{ Capital Specs. } & \multicolumn{3}{|c|}{ Effects of Capital Utilization } \\
\hline & & IAC & $\mathrm{NoC}$ & $\mathrm{CAC}$ & $\mathrm{NAC}$ & $\mathrm{IAC}+\mathrm{CU}$ & $\mathrm{CAC}+\mathrm{CU}$ & $\mathrm{NAC}+\mathrm{CU}$ \\
\hline Variable & \multirow{2}{*}{ U.S. Data } & \multicolumn{7}{|c|}{ Monetary Shocks } \\
\hline \multicolumn{8}{|l|}{ Std. dev. } & \\
\hline GDP* & 1.54 & 1.54 & 1.54 & 1.54 & 1.54 & 1.54 & 1.54 & 1.54 \\
\hline \multicolumn{9}{|l|}{ Std. dev. to GDP } \\
\hline Employment & 0.66 & 1.56 & 1.00 & 1.53 & 1.54 & 1.26 & 1.40 & 1.55 \\
\hline Investment** & 3.38 & 3.39 & - & 3.39 & 5.08 & 3.37 & 3.39 & 5.09 \\
\hline Consumption & 0.81 & 0.81 & 1.07 & 0.49 & 0.03 & 0.44 & 0.37 & 0.03 \\
\hline Net Exports & 0.25 & 0.40 & 0.21 & 0.25 & 0.17 & 0.30 & 0.22 & 0.17 \\
\hline Exports & 2.59 & 1.25 & 1.10 & 1.13 & 1.08 & 1.01 & 1.03 & 1.08 \\
\hline Imports & 3.31 & 3.54 & 1.79 & 2.21 & 1.46 & 2.60 & 1.90 & 1.47 \\
\hline RER & 5.14 & 5.13 & 6.44 & 3.09 & 0.19 & 2.65 & 2.31 & 0.19 \\
\hline \multicolumn{9}{|l|}{ Autocorrelation } \\
\hline GDP & 0.87 & 0.62 & 0.49 & 0.40 & -0.05 & 0.75 & 0.52 & -0.04 \\
\hline Employment & 0.92 & 0.64 & 0.49 & 0.40 & -0.05 & 0.67 & 0.38 & -0.05 \\
\hline Investment & 0.91 & 0.88 & - & 0.43 & -0.04 & 0.84 & 0.42 & -0.04 \\
\hline Consumption & 0.87 & 0.42 & 0.50 & 0.42 & 0.78 & 0.35 & 0.41 & 0.78 \\
\hline Net Exports & 0.83 & 0.86 & 0.70 & 0.69 & 0.21 & 0.86 & 0.67 & 0.21 \\
\hline Exports & 0.85 & 0.69 & 0.52 & 0.45 & -0.03 & 0.72 & 0.44 & -0.03 \\
\hline Imports & 0.84 & 0.87 & 0.70 & 0.70 & 0.20 & 0.86 & 0.67 & 0.21 \\
\hline RER & 0.78 & 0.44 & 0.52 & 0.45 & 0.78 & 0.38 & 0.45 & 0.77 \\
\hline \multicolumn{9}{|l|}{ Cross-correlation } \\
\hline $\mathrm{GDP}^{*}$ & 0.44 & 0.44 & 0.46 & 0.44 & 0.45 & 0.44 & 0.44 & 0.44 \\
\hline Employment & 0.29 & 0.43 & 0.46 & 0.44 & 0.45 & 0.45 & 0.44 & 0.44 \\
\hline Investment & 0.33 & 0.02 & - & 0.24 & 0.30 & 0.10 & 0.25 & 0.29 \\
\hline Consumption & 0.33 & 0.20 & 0.28 & 0.19 & 0.21 & 0.26 & 0.21 & 0.21 \\
\hline \multicolumn{9}{|l|}{ Correlations } \\
\hline GDP, Net Exp. & -0.47 & -0.45 & -0.47 & -0.46 & -0.49 & -0.49 & -0.50 & -0.50 \\
\hline GDP, Exp. & 0.41 & 0.20 & 0.34 & 0.29 & 0.36 & 0.22 & 0.29 & 0.34 \\
\hline GDP, Imp. & 0.82 & 0.62 & 0.79 & 0.73 & 0.88 & 0.68 & 0.78 & 0.88 \\
\hline Exp., Imp. & 0.21 & -0.51 & -0.13 & -0.27 & -0.00 & -0.47 & -0.24 & -0.02 \\
\hline
\end{tabular}

This table reports the selected theoretical moments for each series given our benchmark parameterization. All statistics are computed after each simulated series is H-P filtered (smoothing parameter=1600). NAC denotes the no adjustment cost case, CAC denotes the capital adjustment cost case (which is used in CKM (2002)), IAC denotes the investment adjustment cost case, $+\mathrm{CU}$ indicates that capital utilization in the spirit of Christiano et al. (2005) has been added, and NoC identifies the only variant considered without capital (similar to Steinsson (2008)). We use Matlab 7.4.0 and Dynare v3.051 for the stochastic simulation.

(*) We calibrate the volatility and correlation of monetary shock innovations to match the observed volatility and cross-country correlation of GDP.

$(* *)$ We calibrate the adjustment cost parameter, if the model specification affords us one, to match the observed volatility of investment.

Data Sources: The OECD's Quarterly National Accounts, OECD's Economic Outlook, and OECD's Main Economic Indicators are the most important data sources. Some series are complemented with data from the Bureau of Economic Analysis, the Bureau of Labor Statistics, the Federal Reserve System, the European Central Bank (ECB), and WM/Reuters. For more details, see the description of the dataset in the Appendix. 
Table 3: Simulation Results (Real Shocks).

\begin{tabular}{|c|c|c|c|c|c|c|c|c|}
\hline & & \multicolumn{2}{|c|}{ Benchmark } & \multicolumn{2}{|c|}{ Capital Specs. } & \multicolumn{3}{|c|}{ Effects of Capital Utilization } \\
\hline & & IAC & $\mathrm{NoC}$ & $\mathrm{CAC}$ & NAC & $\mathrm{IAC}+\mathrm{CU}$ & $\mathrm{CAC}+\mathrm{CU}$ & $\mathrm{NAC}+\mathrm{CU}$ \\
\hline Variable & \multirow{2}{*}{ U.S. Data } & \multicolumn{7}{|c|}{ Real Shocks } \\
\hline \multicolumn{8}{|l|}{$\begin{array}{c}\text { Std. dev. } \\
\text { GDP* }\end{array}$} & \\
\hline GDP* & 1.54 & 1.54 & 1.54 & 1.54 & 1.54 & 1.54 & 1.54 & 1.54 \\
\hline \multicolumn{9}{|l|}{ Std. dev. to GDP } \\
\hline Employment & 0.66 & 1.61 & 1.96 & 1.32 & 1.50 & 1.64 & 1.32 & 1.47 \\
\hline Investment** & 3.38 & 3.38 & - & 3.33 & 4.60 & 3.39 & 3.38 & 4.50 \\
\hline Consumption & 0.81 & 0.39 & 0.91 & 0.35 & 0.15 & 0.41 & 0.35 & 0.13 \\
\hline Net Exports & 0.25 & 0.17 & 0.34 & 0.15 & 0.10 & 0.18 & 0.15 & 0.10 \\
\hline Exports & 2.59 & 0.89 & 0.86 & 0.90 & 1.00 & 0.90 & 0.91 & 0.97 \\
\hline Imports & 3.31 & 2.25 & 3.77 & 2.04 & 1.25 & 2.30 & 2.06 & 1.22 \\
\hline RER & 5.14 & 1.64 & 3.14 & 1.51 & 0.56 & 1.72 & 1.53 & 0.52 \\
\hline \multicolumn{9}{|l|}{ Autocorrelation } \\
\hline GDP & 0.87 & 0.91 & 0.85 & 0.89 & 0.54 & 0.91 & 0.90 & 0.53 \\
\hline Employment & 0.92 & 0.48 & 0.61 & 0.32 & -0.10 & 0.48 & 0.31 & -0.10 \\
\hline Investment & 0.91 & 0.94 & - & 0.88 & 0.41 & 0.94 & 0.89 & 0.40 \\
\hline Consumption & 0.87 & 0.82 & 0.84 & 0.84 & 0.75 & 0.82 & 0.84 & 0.75 \\
\hline Net Exports & 0.83 & 0.84 & 0.92 & 0.85 & -0.12 & 0.85 & 0.85 & -0.13 \\
\hline Exports & 0.85 & 0.91 & 0.83 & 0.88 & 0.47 & 0.91 & 0.88 & 0.46 \\
\hline Imports & 0.84 & 0.86 & 0.91 & 0.87 & 0.43 & 0.87 & 0.87 & 0.41 \\
\hline RER & 0.78 & 0.84 & 0.85 & 0.85 & 0.76 & 0.84 & 0.85 & 0.76 \\
\hline \multicolumn{9}{|l|}{ Cross-correlation } \\
\hline $\mathrm{GDP}^{*}$ & 0.44 & 0.44 & 0.46 & 0.44 & 0.46 & 0.44 & 0.44 & 0.46 \\
\hline Employment & 0.29 & 0.47 & 0.60 & 0.40 & 0.42 & 0.47 & 0.39 & 0.42 \\
\hline Investment & 0.33 & 0.57 & - & 0.56 & 0.38 & 0.57 & 0.54 & 0.38 \\
\hline Consumption & 0.33 & 0.65 & 0.76 & 0.64 & 0.70 & 0.65 & 0.62 & 0.70 \\
\hline \multicolumn{9}{|l|}{ Correlations } \\
\hline GDP, Net Exp. & -0.47 & 0.49 & 0.51 & 0.50 & -0.18 & 0.48 & 0.50 & -0.19 \\
\hline GDP, Exp. & 0.41 & 0.64 & 0.81 & 0.63 & 0.47 & 0.64 & 0.62 & 0.47 \\
\hline GDP, Imp. & 0.82 & -0.15 & -0.31 & -0.11 & 0.53 & -0.14 & -0.12 & 0.54 \\
\hline Exp., Imp. & 0.21 & 0.61 & 0.27 & 0.66 & 0.55 & 0.60 & 0.67 & 0.54 \\
\hline
\end{tabular}

This table reports the selected theoretical moments for each series given our benchmark parameterization. All statistics are computed after each simulated series is H-P filtered (smoothing parameter=1600). NAC denotes the no adjustment cost case, CAC denotes the capital adjustment cost case (which is used in CKM (2002)), IAC denotes the investment adjustment cost case, $+\mathrm{CU}$ indicates that capital utilization in the spirit of Christiano et al. (2005) has been added, and NoC identifies the only variant considered without capital (similar to Steinsson (2008)). We use Matlab 7.4.0 and Dynare v3.051 for the stochastic simulation.

$(*)$ We calibrate the volatility and correlation of real shock innovations to match the observed volatility and cross-country correlation of GDP.

(**) We calibrate the adjustment cost parameter, if the model specification affords us one, to match the observed volatility of investment.

Data Sources: The OECD's Quarterly National Accounts, OECD's Economic Outlook, and OECD's Main Economic Indicators are the most important data sources. Some series are complemented with data from the Bureau of Economic Analysis, the Bureau of Labor Statistics, the Federal Reserve System, the European Central Bank (ECB), and WM/Reuters. For more details, see the description of the dataset in the Appendix. 
Table 4: Simulation Results (Investment-Specific Shocks).

\begin{tabular}{|c|c|c|c|c|c|c|c|c|}
\hline \multirow{4}{*}{ Variable } & \multirow{4}{*}{ U.S. Data } & \multicolumn{2}{|c|}{ Benchmark } & \multicolumn{2}{|c|}{ Capital Specs. } & \multicolumn{3}{|c|}{ Effects of Capital Utilization } \\
\hline & & IAC & NoC & $\mathrm{CAC}$ & $\mathrm{NAC}$ & $\mathrm{IAC}+\mathrm{CU}$ & $\mathrm{CAC}+\mathrm{CU}$ & $\mathrm{NAC}+\mathrm{CU}$ \\
\hline & & \multicolumn{7}{|c|}{ Investment-Specific Shocks } \\
\hline & & & & & & & & \\
\hline $\mathrm{GDP}^{*}$ & 1.54 & 1.54 & - & 1.54 & 1.54 & 1.54 & 1.54 & 1.54 \\
\hline \multicolumn{9}{|l|}{ Std. dev. to GDP } \\
\hline Employment & 0.66 & 0.64 & - & 0.65 & 1.58 & 0.73 & 0.68 & 1.58 \\
\hline Investment** & 3.38 & 3.39 & - & 3.39 & 6.42 & 3.78 & 3.82 & 6.40 \\
\hline Consumption & 0.81 & 0.39 & - & 0.40 & 0.37 & 0.43 & 0.41 & 0.37 \\
\hline Net Exports & 0.25 & 0.16 & - & 0.15 & 0.24 & 0.18 & 0.15 & 0.24 \\
\hline Exports & 2.59 & 0.93 & - & 0.94 & 1.12 & 1.04 & 1.04 & 1.12 \\
\hline Imports & 3.31 & 2.04 & - & 1.90 & 2.15 & 2.26 & 2.00 & 2.13 \\
\hline RER & 5.14 & 1.63 & - & 1.79 & 1.93 & 1.77 & 1.85 & 1.94 \\
\hline \multicolumn{9}{|l|}{ Autocorrelation } \\
\hline GDP & 0.87 & 0.96 & - & 0.95 & 0.08 & 0.95 & 0.94 & 0.10 \\
\hline Employment & 0.92 & 0.77 & - & 0.71 & 0.11 & 0.76 & 0.70 & 0.11 \\
\hline Investment & 0.91 & 0.95 & - & 0.92 & 0.24 & 0.95 & 0.93 & 0.25 \\
\hline Consumption & 0.87 & 0.96 & - & 0.96 & 0.70 & 0.95 & 0.96 & 0.70 \\
\hline Net Exports & 0.83 & 0.98 & - & 0.96 & 0.62 & 0.98 & 0.96 & 0.62 \\
\hline Exports & 0.85 & 0.95 & - & 0.94 & 0.16 & 0.95 & 0.95 & 0.17 \\
\hline Imports & 0.84 & 0.97 & - & 0.97 & 0.16 & 0.97 & 0.97 & 0.62 \\
\hline RER & 0.78 & 0.96 & - & 0.93 & 0.70 & 0.97 & 0.94 & 0.70 \\
\hline \multicolumn{9}{|l|}{ Cross-correlation } \\
\hline $\mathrm{GDP}^{*}$ & 0.44 & 0.44 & - & 0.44 & 0.45 & 0.44 & 0.44 & 0.44 \\
\hline Employment & 0.29 & 0.74 & - & 0.69 & 0.44 & 0.72 & 0.67 & 0.44 \\
\hline Investment & 0.33 & 0.47 & - & 0.48 & 0.27 & 0.47 & 0.47 & 0.27 \\
\hline Consumption & 0.33 & 0.65 & - & 0.59 & 0.45 & 0.65 & 0.59 & 0.45 \\
\hline \multicolumn{9}{|l|}{ Correlations } \\
\hline GDP, Net Exp. & -0.47 & 0.31 & - & 0.31 & -0.45 & 0.29 & 0.29 & -0.45 \\
\hline GDP, Exp. & 0.41 & 0.57 & - & 0.31 & 0.31 & 0.56 & 0.55 & 0.31 \\
\hline GDP, Imp. & 0.82 & 0.00 & - & 0.03 & 0.71 & 0.01 & 0.06 & 0.72 \\
\hline Exp., Imp. & 0.21 & 0.52 & - & 0.57 & -0.24 & 0.55 & 0.63 & -0.24 \\
\hline
\end{tabular}

This table reports the selected theoretical moments for each series given our benchmark parameterization. All statistics are computed after each simulated series is H-P filtered (smoothing parameter=1600). NAC denotes the no adjustment cost case, CAC denotes the capital adjustment cost case (which is used in CKM (2002)), IAC denotes the investment adjustment cost case, $+\mathrm{CU}$ indicates that capital utilization in the spirit of Christiano et al. (2005) has been added, and NoC identifies the only variant considered without capital (similar to Steinsson (2008)). We use Matlab 7.4.0 and Dynare v3.051 for the stochastic simulation.

(*) We calibrate the volatility and correlation of investment-specific shock innovations to match the observed volatility and cross-country correlation of GDP.

(**) We calibrate the adjustment cost parameter, if the model specification affords us one, to match the observed volatility of investment.

Data Sources: The OECD's Quarterly National Accounts, OECD's Economic Outlook, and OECD's Main Economic Indicators are the most important data sources. Some series are complemented with data from the Bureau of Economic Analysis, the Bureau of Labor Statistics, the Federal Reserve System, the European Central Bank (ECB), and WM/Reuters. For more details, see the description of the dataset in the Appendix. 
Table 5: Simulation Results (Real and Monetary Shocks).

\begin{tabular}{|c|c|c|c|c|c|c|c|c|}
\hline \multirow{2}{*}{ 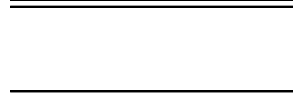 } & & \multicolumn{2}{|c|}{ Benchmark } & \multicolumn{2}{|c|}{ Capital Specs. } & \multicolumn{3}{|c|}{ Effects of Capital Utilization } \\
\hline & & IAC & $\mathrm{NoC}$ & $\mathrm{CAC}$ & NAC & $\mathrm{IAC}+\mathrm{CU}$ & $\mathrm{CAC}+\mathrm{CU}$ & $\mathrm{NAC}+\mathrm{CU}$ \\
\hline Variable & \multirow[t]{2}{*}{ U.S. Data } & \multicolumn{7}{|c|}{ Real + Monetary Shocks } \\
\hline Std. dev. & & & & & & & & \\
\hline $\mathrm{GDP}^{*}$ & 1.54 & 1.54 & 1.54 & 1.54 & 1.54 & 1.54 & 1.54 & 1.54 \\
\hline \multicolumn{9}{|l|}{ Std. dev. to GDP } \\
\hline Employment & 0.66 & 1.61 & 1.42 & 1.52 & 1.54 & 1.37 & 1.41 & 1.54 \\
\hline Investment** & 3.38 & 3.38 & - & 3.34 & 5.04 & 3.38 & 3.39 & 5.04 \\
\hline Consumption & 0.81 & 0.57 & 1.00 & 0.44 & 0.05 & 0.42 & 0.37 & 0.05 \\
\hline Net Exports & 0.25 & 0.28 & 0.28 & 0.24 & 0.16 & 0.24 & 0.21 & 0.16 \\
\hline Exports & 2.59 & 1.04 & 0.99 & 1.05 & 1.07 & 0.96 & 1.00 & 1.07 \\
\hline Imports & 3.31 & 2.82 & 2.95 & 2.36 & 1.45 & 2.37 & 2.10 & 1.45 \\
\hline RER & 5.14 & 3.12 & 5.23 & 2.46 & 0.25 & 2.35 & 2.05 & 0.25 \\
\hline \multicolumn{9}{|l|}{ Autocorrelation } \\
\hline GDP & 0.87 & 0.79 & 0.57 & 0.55 & 0.00 & 0.83 & 0.61 & 0.02 \\
\hline Employment & 0.92 & 0.55 & 0.57 & 0.40 & -0.06 & 0.55 & 0.38 & -0.06 \\
\hline Investment & 0.91 & 0.91 & - & 0.51 & -0.01 & 0.89 & 0.50 & 0.00 \\
\hline Consumption & 0.87 & 0.53 & 0.60 & 0.58 & 0.76 & 0.50 & 0.58 & 0.76 \\
\hline Net Exports & 0.83 & 0.86 & 0.85 & 0.74 & 0.20 & 0.86 & 0.72 & 0.20 \\
\hline Exports & 0.85 & 0.79 & 0.59 & 0.53 & 0.01 & 0.80 & 0.52 & 0.02 \\
\hline Imports & 0.84 & 0.87 & 0.87 & 0.78 & 0.22 & 0.86 & 0.76 & 0.22 \\
\hline RER & 0.78 & 0.50 & 0.57 & 0.55 & 0.77 & 0.48 & 0.55 & 0.77 \\
\hline \multicolumn{9}{|l|}{ Cross-correlation } \\
\hline $\mathrm{GDP}^{*}$ & 0.44 & 0.45 & 0.44 & 0.44 & 0.44 & 0.44 & 0.44 & 0.44 \\
\hline Employment & 0.29 & 0.47 & 0.47 & 0.43 & 0.44 & 0.44 & 0.43 & 0.43 \\
\hline Investment & 0.33 & 0.36 & - & 0.33 & 0.30 & 0.31 & 0.33 & 0.29 \\
\hline Consumption & 0.33 & 0.41 & 0.45 & 0.39 & 0.54 & 0.38 & 0.38 & 0.54 \\
\hline \multicolumn{9}{|l|}{ Correlations } \\
\hline GDP, Net Exp. & -0.47 & -0.04 & 0.11 & -0.14 & -0.48 & -0.19 & -0.22 & -0.48 \\
\hline GDP, Exp. & 0.41 & 0.46 & 0.51 & 0.41 & 0.36 & 0.38 & 0.39 & 0.35 \\
\hline GDP, Imp. & 0.82 & 0.21 & 0.06 & 0.34 & 0.85 & 0.36 & 0.43 & 0.85 \\
\hline Exp., Imp. & 0.21 & -0.02 & 0.09 & 0.01 & 0.03 & -0.04 & 0.02 & 0.03 \\
\hline
\end{tabular}

This table reports the selected theoretical moments for each series given our benchmark parameterization (with monetary and real shocks). All statistics are computed after each simulated series is H-P filtered (smoothing parameter $=1600$ ). NAC denotes the no adjustment cost case, CAC denotes the capital adjustment cost case (which is used in CKM (2002)), IAC denotes the investment adjustment cost case, +CU indicates that capital utilization in the spirit of Christiano et al. (2005) has been added, and NoC identifies the only variant considered without capital (similar to Steinsson (2008)). We use Matlab 7.4.0 and Dynare v3.051 for the stochastic simulation.

(*) We assume that real shocks are 4 times as volatile as monetary shocks (see Søndergaard, 2004), and we assume that the cross-country correlation of real shocks is identical to that of monetary shocks. Then, we calibrate the volatility and correlation of real shock innovations to match the observed volatility and cross-country correlation of GDP.

$(* *)$ We calibrate the adjustment cost parameter, if the model specification affords us one, to match the observed volatility of investment.

Data Sources: The OECD's Quarterly National Accounts, OECD's Economic Outlook, and OECD's Main Economic Indicators are the most important data sources. Some series are complemented with data from the Bureau of Economic Analysis, the Bureau of Labor Statistics, the Federal Reserve System, the European Central Bank (ECB), and WM/Reuters. For more details, see the description of the dataset in the Appendix. 
Table 6: Variance Decomposition (Real and Monetary Shocks).

\begin{tabular}{lcccc}
\hline \hline & \multicolumn{4}{c}{ Benchmark (IAC) } \\
& Monetary Shocks & Real Shocks \\
\hline Variable & Domestic & Foreign & Domestic & Foreign \\
\cline { 2 - 5 } Domestic GDP & 42.71 & 0.19 & 57.07 & 0.03 \\
Foreign GDP & 9.84 & 33.06 & 9.68 & 47.42 \\
Domestic Employment & 40.12 & 0.11 & 59.75 & 0.02 \\
Foreign Employment & 8.90 & 31.33 & 11.26 & 48.52 \\
Domestic Investment & 44.92 & 1.40 & 53.40 & 0.28 \\
Foreign Investment & 4.12 & 42.20 & 12.72 & 40.96 \\
Domestic Consumption & 69.46 & 0.47 & 29.61 & 0.46 \\
Foreign Consumption & 9.85 & 60.07 & 8.50 & 21.58 \\
Net Exports & 21.29 & 52.76 & 7.46 & 18.49 \\
Exports & 4.37 & 54.47 & 16.76 & 24.40 \\
Imports & 29.50 & 28.51 & 2.44 & 39.54 \\
RER & 23.31 & 57.77 & 5.44 & 13.48 \\
\hline \hline
\end{tabular}

This table reports the variance decomposition for each series given our benchmark parameterization (with both monetary and real shocks). All statistics are computed after each simulated series is H-P filtered (smoothing parameter $=1600$ ). IAC denotes the investment adjustment cost specification, which is our specification of reference. Each column indicates the fraction of the variance coming from respectively a domestic monetary shock, a foreign monetary shock, a domestic real shock and a foreign real shock. We use Matlab 7.4.0 and Dynare v3.051 for the stochastic simulation.

Net exports, exports and imports are computed from the perspective of the domestic country. The real exchange rate (RER) is also consistently defined in the paper. 
Figure 1: Impulse Response Functions for a Domestic Monetary Shock.
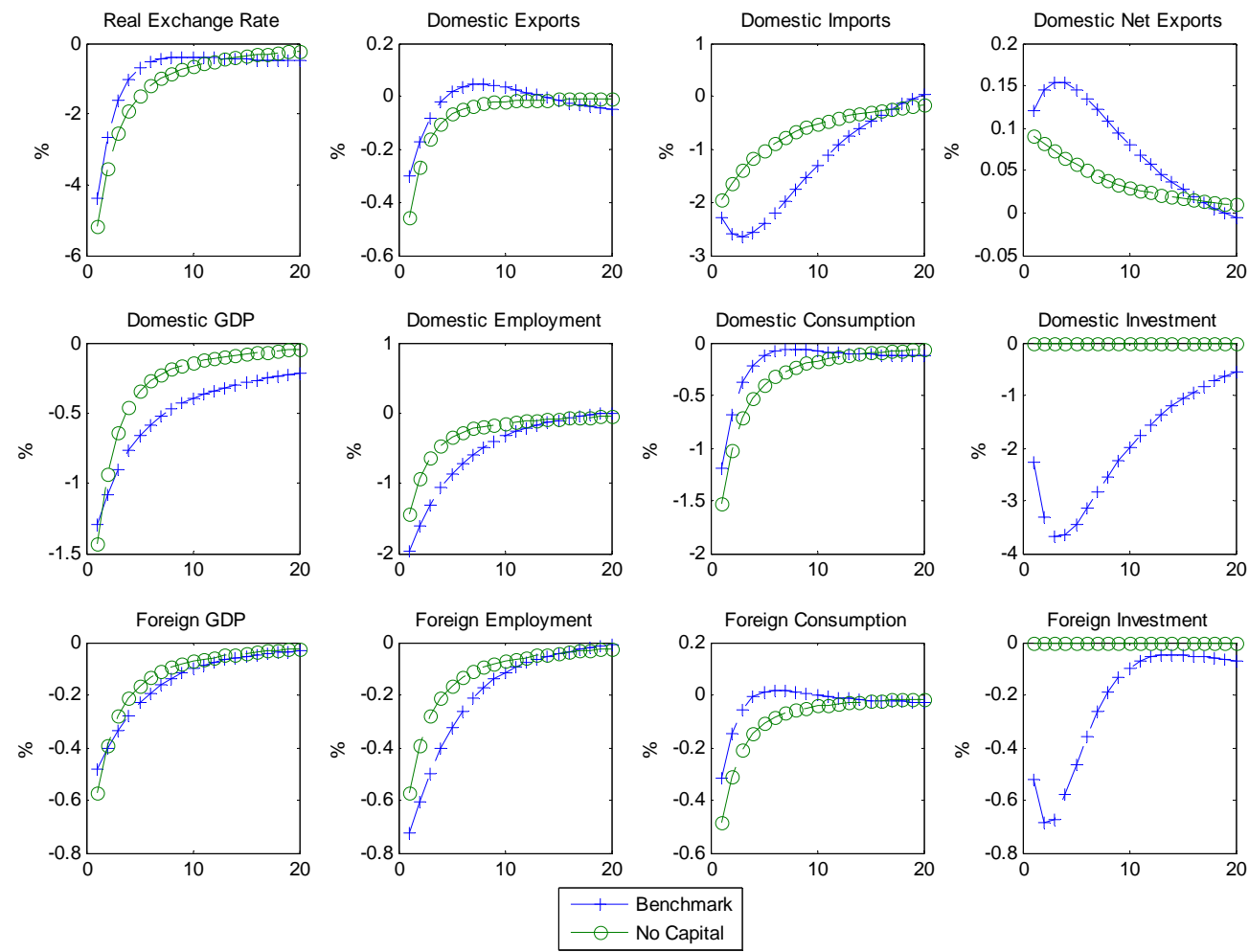

These graphs report the selected impulse response functions (IRFs) for each series given our benchmark parameterization. The IRFs represent the response of the endogenous variables to a one time, one standard deviation domestic monetary shock innovation. The benchmark identifies the IAC model with capital, which is our specification of reference. No Capital, which we also denote NoC, offers an alternative where capital is not available and technologies are linear-in-labor (similar to Steinsson (2008)). We use Matlab 7.4.0 and Dynare v3.051 for the stochastic simulation. 


\section{Figure 2: Impulse Response Functions for a Domestic Real Shock.}
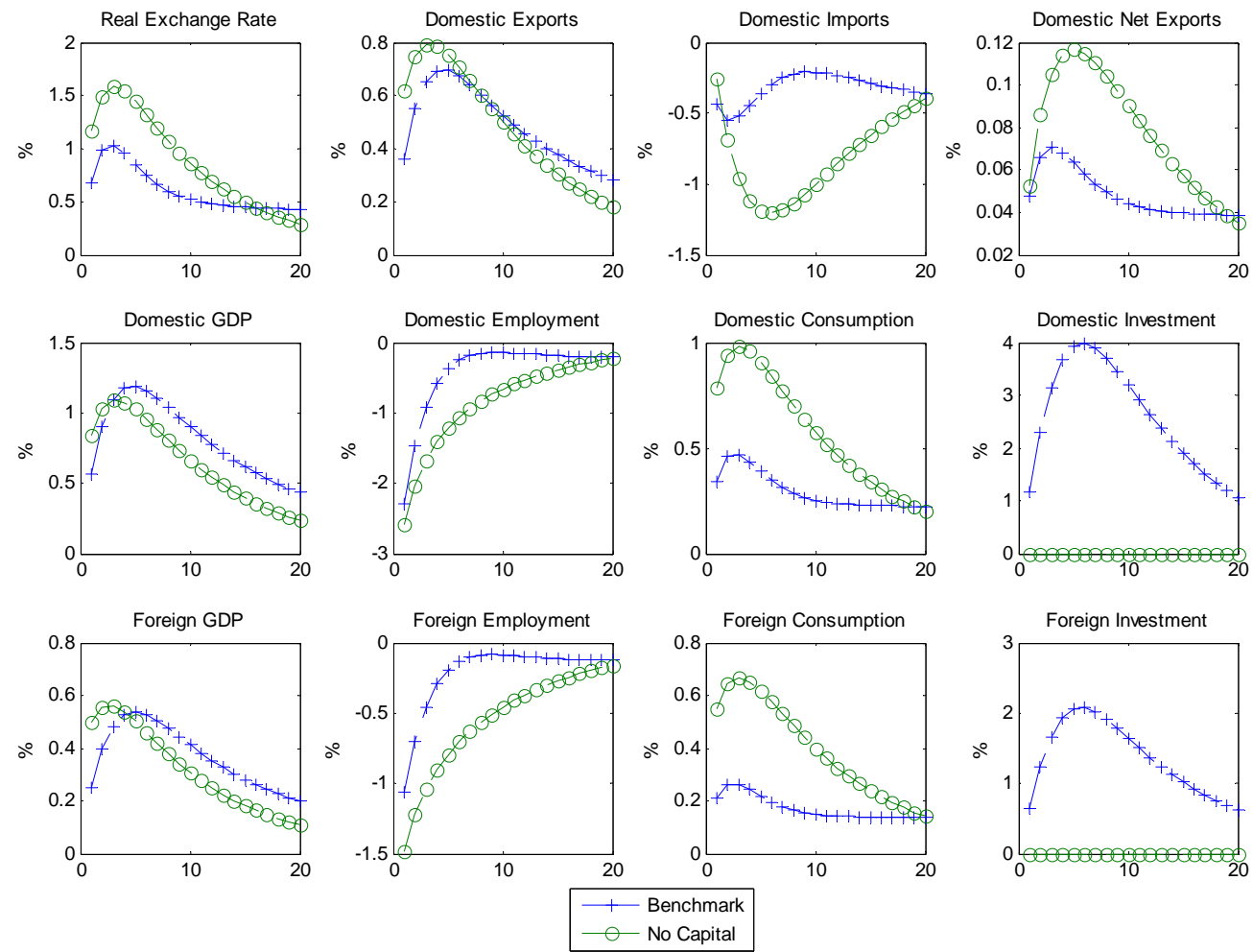

These graphs report the selected impulse response functions (IRFs) for each series given our benchmark parameterization. The IRFs represent the response of the endogenous variables to a one time, one standard deviation domestic real shock innovation. The benchmark identifies the IAC model with capital, which is our specification of reference. No Capital, which we also denote NoC, offers an alternative where capital is not available and technologies are linear-in-labor (similar to Steinsson (2008)). We use Matlab 7.4.0 and Dynare v3.051 for the stochastic simulation. 
Figure 3: Impulse Response Functions for a Domestic Investment-Specific Shock.
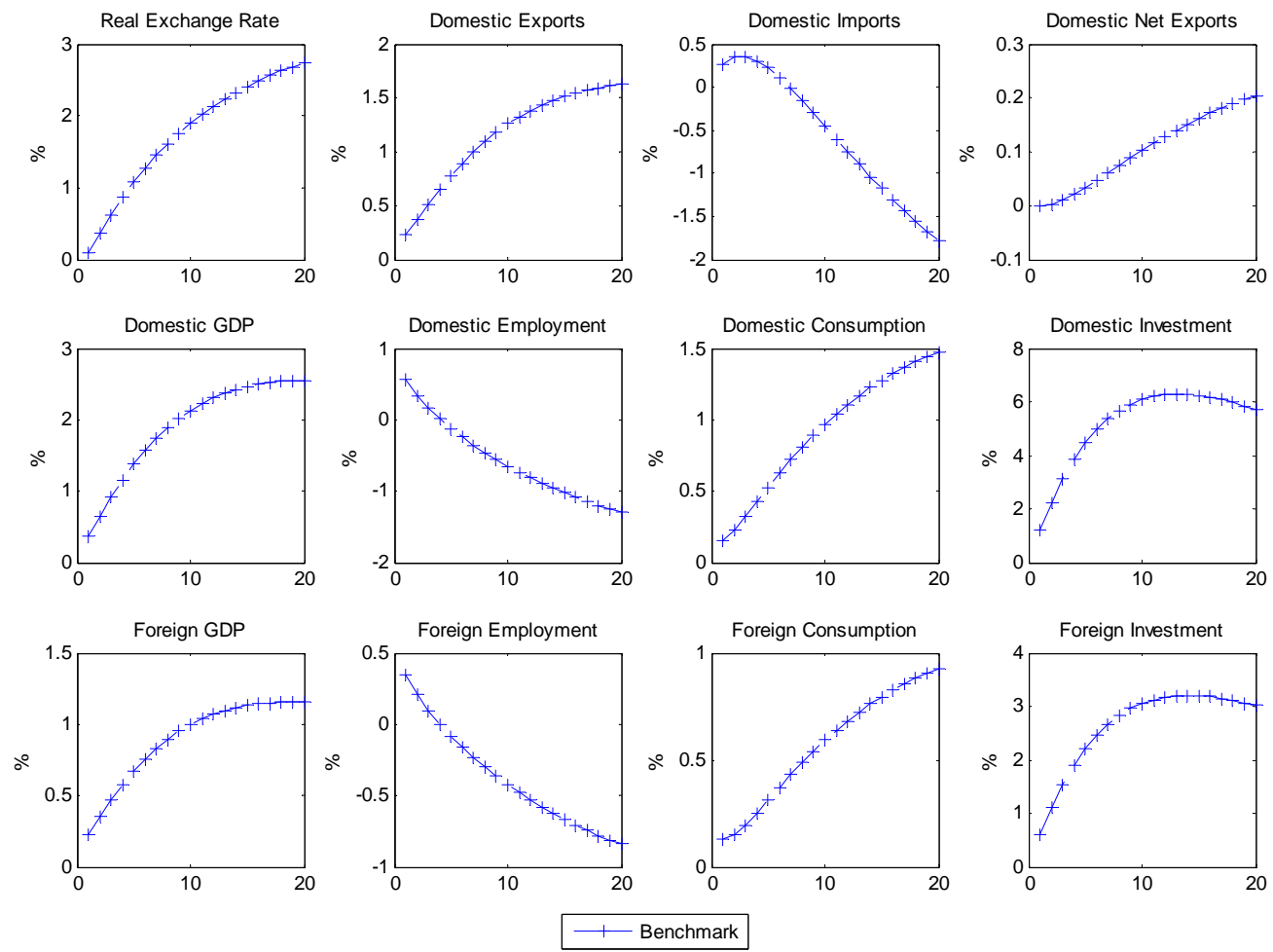

These graphs report the selected impulse response functions (IRFs) for each series given our benchmark parameterization. The IRFs represent the response of the endogenous variables to a one time, one standard deviation domestic investment-specific shock innovation. The benchmark identifies the IAC model with capital, which is our specification of reference. We use Matlab 7.4.0 and Dynare v3.051 for the stochastic simulation. 